\title{
The Interaction of Morphology and Syntax in Affix Order
}

\author{
Jochen Trommer
}

\section{Introduction}

In this article, I propose a constraint-based account of ordering restrictions on subject agreement affixes. Different orderings of subject agreement, crosslinguistically and in single languages, are captured by different rankings of universal well-formedness constraints in the sense of Optimality Theory (OT, Prince and Smolensky 1993). Assuming a postsyntactic morphology module as in Distributed Morphology (DM, Halle and Marantz 1993), I argue that part of these constraints are purely morphological while others require the correspondence of affix order to the underlying syntactic structure. Constraint interaction of this type obviates any stipulation for whether single agreement affixes appear as prefixes or suffixes, and reduces seemingly idiosyncratic facts to general principles. The theoretical results are based on empirical findings from a corpus of about 100 languages with subject agreement. The sample as well as the analysis focus on agreement patterns where subject agreement is split into person and number markers. Data of this type have been largely ignored in the literature on affix order, but prove essential for establishing morphological constraints whose effects can also be found in "standard" types of agreement.

\subsection{Affixal Status and Alignment}

What is systematic about affix order in the following data from Georgian? ${ }^{1}$

$$
\begin{array}{llll}
v \text {-xedav } & v \text {-xedav-t } & \text { xedav-s } & \text { xedav-en } \\
\text { S1-see } & \text { S1-see-PL } & \text { see-S3s } & \text { see-S3p } \\
\text { 'I see' } & \text { 'we see' } & \text { 'he sees' } & \text { 'they see' }
\end{array}
$$


Distributed Morphology, like most current accounts of inflectional morphology, would state for each affix whether it is a prefix $(v-)$ or a suffix $(-t,-d$, -en). This is unsatisfying even under a purely descriptive perspective. A more parsimonious account would state that subject agreement affixes in Georgian are generally suffixes with the exception of $v$, which is a prefix. This interaction of a general rule and an exception statement can be naturally formalized by ranked violable constraints as in (2), where (2b) can only apply if $(2 \mathrm{a})$ does not
a. $\quad v$ is a prefix
b. Subject agreement affixes are suffixes

These constraints are ranked because the higher ranked constraint (2a) has to be obeyed in case of conflict, and violable since (2b) is then violated. But we can still do better and ask if there is a deeper reason why $v$-is a prefix but not - $t$ or - en. Indeed, looking at the languages of the world (cf. section 4), one finds a general tendency for number agreement to be marked on the right and for person agreement to be marked on the left edge of the word. Thus (2) can be replaced by (3):

a. Number agreement should be maximally rightwards
b. Person agreement should be maximally leftwards

Constraints of this type, which require minimal distance between edges (in (3a) between the right edge of number affixes and the right edge of the word, in (3b) between the left edge of person affixes and the left edge of the word), are called "alignment constraints" in the OT-literature (McCarthy and Prince 1993$)^{2}$ and are independently motivated by applications in a big number of other linguistic domains (see section 4.4.2). The constraints in (3) clearly predict the order in $v$-xedav-t, because $v$ - marks only person (1st) and - $t$ only number (plural), but what about -en and $-s$ ? Since these mark person and number, both constraints are relevant. Again, since (3a) is ranked higher than (3b) they are rightwards. Note that we have now completely reversed our original viewpoint: The position of $v$-, which at first seemed to be an idiosyncratic fact about a single affix, now appears as a phenomenon familiar from the literature on Optimality Theory, namely Emergence of the Unmarked (McCarthy and Prince 1994): Universal wellformedness-constraints (in this case (3b)) become visible in a language only under restricted circumstances (the unique featural content of $v$ - as pure person marker), blocked 
otherwise by higher-ranked constraints (here (3a)).

Following the logic of OT, constraints, while themselves universal, can be ranked differently in different languages. Thus we would also expect a language where pure number and pure person markers are positioned as in Georgian but where mixed markers are prefixes. As we will see in section 4, this prediction is borne out in other languages such as Muna and Amharic.

However data from Island Kiwai (Wurm 1975) show that alignment cannot be the only crucial factor to account for the order of agreement affixes: ${ }^{3}$

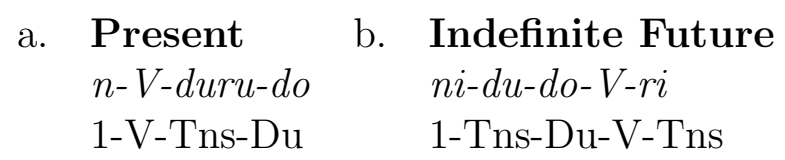

While the dual marker $d o$ is a suffix in the present tense (4a), as expected, it is a prefix in the indefinite future (4b). Note however that - do is always right-adjacent to a Tense affix (-duru in (4a), $d u$ - in (4b)). I propose to connect this observation to the fact that in most languages agreement seems to be adjoined to a Tense head (Halle and Marantz 1993: 146). As we will see in section 6, the interaction of a further constraint, REFLECT(Agr) requiring that the order of agreement affixes reflects the position of their underlying syntactic host - with alignment constraints accounts for the facts in Kiwai as well as for further crosslinguistic generalizations on the order of subject agreement affixes.

\subsection{Overview}

In section 2, I will sketch the formal framework I assume. Section 3 introduces the language sample I use. The results on person and number agreement will be presented in section 4, where I also develop an analysis in terms of alignment constraints. In section 5, I will show, based on Julien (2000), that syntactic heads such as Tense and Aspect follow quite different principles which result from the nature of possible movement operations in syntax. In the following two sections, it is shown how syntactic and morphological constraints interact to derive the order of Tense and agreement in the grammars of single languages (section 6) and in form of universal tendencies in affix order (section 7). In section 8, I argue that the analysis is consistent with findings on the relation of affix order and basic word order, and section 9 shows that it is empirically superior to alternative approaches to 
affix order. The paper concludes with some speculations on the asymmetry between morphology and syntax in affix order (section 10). An appendix lists the languages of my language sample including genetic and areal affiliation and the sources used.

\section{The Framework}

The framework I assume in this paper is Distributed Optimality (DO, Trommer 2002a, Trommer 2002b). DO is a constraint-based, modular version of Distributed Morphology (DM, Halle and Marantz 1993). The name Distributed Optimality refers to the assumption of different morphosyntactic components, all mapping specific inputs to outputs according to the principles of Optimality Theory (OT, Prince and Smolensky 1993, McCarthy and Prince 1994). In section 2.1, I briefly discuss the architecture of the grammar in DO. In 2.2, I introduce some basic notions of OT and alignment constraints as the basic constraint type to account for the order of agreement affixes.

\subsection{The Architecture of the Grammar}

In DO, morphosyntax involves the following three modules:
a. Syntax (lexical items $\Rightarrow$ syntactic chains)
b. Chain Interpretation (syntactic chains $\Rightarrow$ single heads)
c. Head Interpretation (heads $\Rightarrow$ vocabulary items)

The Syntax component creates abstract syntactic representations which contain neither agreement nor case affixes (while chains might be assigned abstract case). Crucially, Syntax creates chains from lexical items. Chain Interpretation maps chains onto single heads (put another way, traces, i.e., copies produced by movement are eliminated) and adds (abstract) case and agreement heads. As Syntax, this module does not involve phonological features. Finally, in Head Interpretation, the abstract heads from Chain Interpretation are mapped to (possibly underspecified) Vocabulary Items which introduce phonological material. (6) illustrates this model for the German sentence wir trinken, "we drink":

$$
\text { a. }[+\mathrm{D}+1+\mathrm{pl}]_{i}[+\mathrm{Tns}]\left[[+\mathrm{D}+1+\mathrm{pl}]_{i}[+\mathrm{V}]\right]_{V P}
$$




$$
\begin{aligned}
& \text { b. } \quad[+\mathrm{D}+1+\mathrm{pl}][+\mathrm{Nom}]][+\mathrm{Tns}][[+\mathrm{D}+1+\mathrm{pl}][[+\mathrm{V}][+\mathrm{Agr}+1+\mathrm{pl}]]]_{V P} \\
& \text { c. wir: }[+\mathrm{D}+1+\mathrm{pl}] \quad \operatorname{trink}:[+\mathrm{V}] \quad \text { en: }[+\mathrm{Agr}+\mathrm{pl}]
\end{aligned}
$$

The syntax generates the representation in (6a). There is a chain comprising two instances of the pronoun $([+\mathrm{D}+1+\mathrm{pl}])$, one in the specifier of IP and the other in its base position in the VP. ${ }^{4}$ Chain Interpretation maps this chain onto (6b), where the chain is reduced to the single head in Spec IP to which the $[+\mathrm{Nom}]$ head is added. To $\mathrm{V}$ an agreement head is adjoined. Finally, the heads are interpreted by the vocabulary items, such as $e n:[+\mathrm{Agr}+\mathrm{pl}]$.

An aspect of DO that is crucial for the following discussions is the assumption taken over from DM that agreement has a very special status in the grammar. While Tense as a lexical head is already present in the syntactic module, agreement is only inserted at Chain Interpretation. Moreover agreement also allows splitting at Head Interpretation ${ }^{5}$. Thus, as we saw in (1), Georgian subject agreement is sometimes expressed by a single affix such as $-e n, 3 \mathrm{pl}$ and sometimes by two affixes, where person and number is split as in $v-\ldots-t$.

To account for the complementary distribution of "fused" and "split" agreement, I assume with Noyer (1992) that there is in both cases just one agreement head at Chain Interpretation (7a), which corresponds to one or two vocabulary items at Head Interpretation (7b).

$$
\begin{array}{ccc}
\text { a. } & {[+\mathrm{V}]_{1}[+1+\mathrm{pl}]_{2}} & {[+\mathrm{V}]_{1}[+3+\mathrm{pl}]_{2}} \\
\text { b. } & \text { v: }[+1+2]_{2} \text { xedav: }[+\mathrm{V}]_{1} \text { t: }[+\mathrm{pl}]_{2} & \text { xedav: }[+\mathrm{V}]_{1} \text { en: }[+\mathrm{pl}]_{2}
\end{array}
$$

If this analysis is correct, split agreement is of special interest for an account of affix order, since the respective order of $v:[+1]$ and $t:[+\mathrm{pl}]$ cannot follow from any syntactic principle applying in the synchronic grammar of Georgian. Agreement is not a head in syntax proper, and even if it is at Chain Interpretation, the vocabulary items at Head Interpretation are just different parts of this head. Since the features of a head are unordered, all principles that regulate the relative order of affixes corresponding to these features must be non-syntactic, hence morphological.

Note that in DO there are no words in the traditional sense. However, many morphological processes refer to the Spell-out-domain, a small wordlike unit which consist of a lexical head and all string-adjacent functional categories from its extended projection (see Trommer 2002a for further discussion) at Head Interpretation. 


\subsection{Optimality Theory and Alignment Constraints}

Optimality Theory Prince and Smolensky (1993) is a general formal framework based on the assumption of universal violable constraints, which instantiate by different rankings grammars of individual languages. OT-constraints assign to candidates sets of constraint violations. Thus, the constraints from (3) can be restated more formally as the alignment constraints in (8): ${ }^{6}$

(8) a. $[+\mathrm{NUM}] \Rightarrow \mathrm{R}$ (Count a constraint violation for each vocabulary item between a vocabulary item specifying a number feature and the right edge of the spell-out domain.)

b. L $\leftrightarrow[+\mathrm{PER}]$ (Count a constraint violation for each vocabulary item between a vocabulary item specifying a person feature and the left edge of the spell-out domain.)

Constraints evaluate possible candidates. This process is usually depicted in a tableau like (9) for the Georgian verb form v-xedav-t, we see:

$v$-xedav-t, 'we see'

\begin{tabular}{|r||l|l|}
\hline & NUM $\Rightarrow$ R & L $\bullet$ PER \\
\hline \hline v-xedav-t & & \\
\hline xedav-v-t & & $* !$ \\
\hline xedav-t-v & $* !$ & $* *$ \\
\hline v-t-xedav & $* !$ & \\
\hline
\end{tabular}

Constraint violations are marked by "**. Constraint evaluation starts with the highest-ranked constraint (NUM $\Rightarrow \mathrm{R}$ ), which eliminates all candidates where the number affix $t$ is not at the right edge (xedav-t-v and $v$-t-xedav). Elimination of suboptimal candidates is depicted by "!" after the responsible constraint violation. The second constraint, L $\$$ PER, eliminates now xedav$v$ - $t$ ( 1 violation), since this is less harmonic than $v$-xedav-t which involves no violation at all.

A major claim of OT is that all constraints are universal and languages differ only by instantiating different rankings of these constraints. In the following sections, I try to show that this also holds for alignment constraints on subject agreement. 


\section{The Language Sample}

Split subject agreement and languages where Tense and agreement are both prefixes (these will become relevant in section 7 ) are relatively rare. For this reason, the sample is intended to maximize the number of languages which exhibit these patterns, since my goal is not to test the frequency of these patterns, but different properties of these patterns. On the other hand, I have tried to find instances for all patterns in as many genetically diverse language families as possible according to the classification of Ruhlen (1987).

A second problem is to differentiate subject agreement from similar grammatical markers such as cliticized pronouns, especially in so-called pronominalargument languages where agreement affixes seem to make genuine arguments of the verb superfluous. ${ }^{7}$ In the sample, I have counted all those markers as agreement that encode obligatorily person and/or number features of the subject and are bound to a verb. This excludes genuinely verbal plural markers which express verbal categories such as iterative or intensity of action, but might be taken as plural agreement in a superficial analysis (cf. Durie 1986). In cases of ergative systems I included the marker agreeing with the absolutive argument. Finally, I did not consider languages where SAgr is fused to a high degree with other categories like Tense and Aspect. ${ }^{8}$

\section{The Order of Person and Number Agree- ment}

\subsection{Methodology}

Determining the relative order of subject person and number agreement faces the problem that person and number markers are often fused, i.e., number markers also specify person values or vice versa. I try to solve the problem by including all cases into consideration where one agreement affix marks only one category $C_{1}$ (person or number) while the other affix marks the other one, $C_{2}$, and possibly also $C_{1}$, as in (10):

$$
\begin{array}{ll}
\text { a. } & \text { Aff }_{1}[+\mathrm{PER}] \mathrm{Aff}_{2}[+\mathrm{NUM}] \\
\text { b. } & \text { Aff }_{1}[+\mathrm{PER}+\mathrm{NUM}] \mathrm{Aff}_{2}[+\mathrm{NUM}] \\
\text { c. } & \text { Aff }_{1}[+\mathrm{PER}] \text { Aff } \\
2+\mathrm{PER}+\mathrm{NUM}]
\end{array}
$$


Linear precedence between affixes is determined straightforwardly in cases where the affixes cooccur Where they cannot, precedence is determined by the relative position of the PER/NUM affixes with respect to a third unit. E.g. the Georgian 3pl suffix -en $([+\mathrm{PER}+\mathrm{NUM}])$ is said to follow the 1sg prefix $v$ - $([+\mathrm{PER}])$ since the first follows the stem and the latter precedes it, even though this never happens in the same form.

I try to remedy the problem of scarcity of the data by including different patterns from single or closely related languages. Thus, Quechua is included twice in the sample since there are varieties with the order $\mathrm{P}>\mathrm{N}(\mathrm{P}(\mathrm{erson})$ precedes $(\mathrm{N})$ umber) and others with $\mathrm{N}>\mathrm{P}((\mathrm{N})$ umber precedes $\mathrm{P}($ erson $)$ ). Two patterns are said to be different if they involve different orders or different sub-cases of (10).

\subsection{Results}

In the language sample, there are 58 languages exhibiting splits in person/number marking. These show 80 different ordering patterns. 11 of these patterns include only prefixes, 28 only suffixes, and 39 are mixed (one is a prefix, and one is a suffix):

$$
\begin{aligned}
& \text { Ordering Patterns } \\
& 10 \text { both prefix } 12.5 \% \\
& 30 \text { both suffix } 37.5 \% \\
& 40 \text { mixed } \quad 50.0 \%
\end{aligned}
$$

What is interesting here is that the mixed cases constitute one half of the patterns. (12) contains the relative percentages of Person $>$ Number $(\mathrm{P}>$ $\mathrm{N})$, and Number $>$ Person $(\mathrm{N}>\mathrm{P})$ for all patterns. Note that $\mathrm{P}>\mathrm{N}$ is the dominant order, no matter which of both affixes is a prefix or a suffix.

All Patterns

\begin{tabular}{|l||ll|ll|ll||ll|}
\hline & \multicolumn{2}{|c||}{ both prefix } & \multicolumn{2}{|c|}{ both suffix } & \multicolumn{2}{|c|}{ mixed } & \multicolumn{2}{c|}{ all } \\
\hline \hline $\mathrm{P}>\mathrm{N}$ & 9 & $90.0 \%$ & 22 & $73.3 \%$ & 39 & $97.5 \%$ & 70 & $87.5 \%$ \\
\hline $\mathrm{N}>\mathrm{P}$ & 1 & $10.0 \%$ & 8 & $26.7 \%$ & 1 & $2.5 \%$ & 10 & $12.5 \%$ \\
\hline sum & 10 & & 30 & & 40 & & 80 & \\
\hline
\end{tabular}


The same results hold if we look only at the affixes marking person or number, but not both, i.e., if all patterns involving Person/Number markers (PN) are excluded:

$$
\text { Only P,N (PN excluded) }
$$

\begin{tabular}{|l||ll|ll|ll||ll|}
\hline & \multicolumn{2}{|c||}{ both prefix } & \multicolumn{2}{|c||}{ both suffix } & \multicolumn{2}{|c|}{ mixed } & \multicolumn{2}{c|}{ all } \\
\hline \hline $\mathrm{P}>\mathrm{N}$ & 8 & $88.9 \%$ & 17 & $77.3 \%$ & 25 & $100 \%$ & 50 & $89.3 \%$ \\
\hline $\mathrm{N}>\mathrm{P}$ & 1 & $11.1 \%$ & 5 & $22.7 \%$ & 0 & $0 \%$ & 6 & $10.7 \%$ \\
\hline sum & 9 & & 22 & & 25 & & 56 & \\
\hline
\end{tabular}

A possible source of error are person and number affixes which are always string-adjacent whenever they cooccur. A complex of such affixes could actually be a simple affix. The following table counts only affixes which are in some instances separated ${ }^{9}$

(14) Separated Affixes

\begin{tabular}{|l|ll|ll|ll||ll|}
\hline & \multicolumn{2}{|c|}{ both prefix } & \multicolumn{2}{|c||}{ both suffix } & \multicolumn{2}{|c||}{ mixed } & \multicolumn{2}{|c|}{ all } \\
\hline \hline $\mathrm{P}>\mathrm{N}$ & 2 & $100.0 \%$ & 10 & $66.6 \%$ & 39 & $97.5 \%$ & 51 & $89.5 \%$ \\
\hline $\mathrm{N}>\mathrm{P}$ & 0 & $0.0 \%$ & 5 & $33.3 \%$ & 1 & $2.5 \%$ & 6 & $10.5 \%$ \\
\hline sum & 2 & & 15 & & 40 & & 57 & \\
\hline
\end{tabular}

Finally, the language sample contains a number of languages which have number but no person markers. Here, from 6 languages, the number marker is in 5 languages $(83 \%)$ a suffix.

\subsection{Analysis}

The core of my account for the PER-NUM asymmetry (the fact that person agreement tends to precede number agreement) are the two already familiar alignment constraints in (15):

a. L $\boldsymbol{S}[+\mathrm{PER}]$ (Person-Agreement is at the left edge.)

b. $[+\mathrm{NUM}] \Rightarrow \mathrm{R}$ (Number-Agreement is at the right edge.)

Considering the possible orders of simple number and person affixes with respect to a verbal stem $(\mathrm{V})$, we get the possibilities in (16). The best candidate under each ranking is $\mathrm{P}>\mathrm{V}>\mathrm{N}$, which corresponds closely to the empirical results, where this is the overall favored ordering of person and 
number. The orders $\mathrm{P}>\mathrm{N}>\mathrm{V}$ and $\mathrm{V}>\mathrm{P}>\mathrm{N}$ each induce one constraint violation:

Syntagmatic patterns of $\mathrm{P}$ and $\mathrm{N}$

\begin{tabular}{|c|c|c|c|c|}
\hline & L $<$ PER & NUM $\Rightarrow \mathrm{R}$ & bounded by & Data \\
\hline 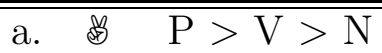 & & & - & 24 \\
\hline b. 䁏 $\quad \mathrm{V}>\mathrm{P}>\mathrm{N}$ & $*$ & & a. & 17 \\
\hline c. 罡 $\quad \mathrm{P}>\mathrm{N}>\mathrm{V}$ & & $*$ & a. & 8 \\
\hline d. $\quad \mathrm{V}>\mathrm{N}>\mathrm{P}$ & $*$ & $* *$ & a.,c. & 5 \\
\hline e. $\quad \mathrm{N}>\mathrm{P}>\mathrm{V}$ & $* *$ & $*$ & a.,b. & 1 \\
\hline f. † $N>V>P$ & $* *$ & $* *$ & a.,b.,c.d.,e. & 0 \\
\hline
\end{tabular}

The 4th column in the table states for each candidate by which candidates it is harmonically bounded (Samek-Lodovici and Prince 1999: 2, and references there), i.e., which candidates are more harmonic under all possible constraint rankings. A candidate $C$ harmonically bounds $C^{\prime}$ iff $C$ does not induce more constraint violations than $C^{\prime}$ on any constraint, and $C^{\prime}$ induces at least one more constraint violation than $C$ for at least one constraint. Thus, as far as the alignment constraints are involved, (16c) can never be more harmonic than (16a). This imposes a natural fitness metric on the candidates which is indicated here by the symbols by this metric corresponds closely to the empirical data from the language sample. The number of corresponding languages can be found in the fifth column. By the more other candidates a candidate is harmonically bounded, by the less language patterns it is represented in the sample. The most important result is that the pattern $\mathrm{P}>\mathrm{V}>\mathrm{N}$ is the overall favored one, both in the sample and in the order imposed by the constraints.

Taking a different perspective, we can look for the best order of PER/NUM affixes if this order is already partially determined by other constraints. Assume that $\mathrm{P}$ and $\mathrm{N}$ are necessarily prefixes because otherwise some highranked third constraint would be violated. This means that we only have the options (16c) and (16e), in which case c. always will be preferred:

(17) Syntagmatic patterns of P and N (prefixes)

\begin{tabular}{|c|c|c|c|c|}
\hline & L 2 PER & $\mathrm{NUM} \Rightarrow \mathrm{R}$ & bounded by & Data \\
\hline $\begin{array}{lll}\text { c. } & \mathrm{P}>\mathrm{N}>\mathrm{V}\end{array}$ & & 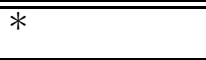 & a. & 8 \\
\hline e. $\quad \mathrm{N}>\mathrm{P}>\mathrm{V}$ & $* *$ & $*$ & a.,b. & 1 \\
\hline
\end{tabular}


In a mirror fashion, if some high-ranked constraint forces both $\mathrm{P}$ and $\mathrm{N}$ to be suffixal, we get $(16 \mathrm{~b}, \mathrm{~d})$ as candidates, where the first always out-ranks the latter:

(18) Syntagmatic patterns of P and N (suffixes)

\begin{tabular}{|c|c|c|c|c|}
\hline & L 2 PER & NUM $\Rightarrow \mathrm{R}$ & bounded by & Data \\
\hline b. $\quad$ 国 $\quad \mathrm{V}>\mathrm{P}>\mathrm{N}$ & ** & & a. & $\overline{17}$ \\
\hline d. $\quad \mathrm{V}>\mathrm{N}>\mathrm{P}$ & $*$ & $* *$ & a.,c. & 5 \\
\hline
\end{tabular}

If no such restrictions are imposed on $\mathrm{P}$ and $\mathrm{N}, \mathrm{P}>\mathrm{V}>\mathrm{N}$ is the optimal candidate. Similar results are obtained for the orders where P and N are partially fused and for the case where orders are determined paradigmatically. See Trommer (2002a) for details.

So far, the assumption of two alignment constraints makes two predictions, namely that $\mathrm{P}>\mathrm{V}>\mathrm{N}$ is the overall favored pattern and that the PER-NUM asymmetry should hold. The latter results from the fact that for all constellations $(\mathrm{P} / \mathrm{N}, \mathrm{PN} / \mathrm{N}, \mathrm{PN} / \mathrm{P}$, paradigmatic or syntagmatic) the candidates conforming to this generalization always harmonically bound the candidates violating it. The account makes two further predictions: Languages with number agreement should only have suffixal agreement markers since L $\&$ PER is irrelevant here. This is illustrated in (19) where the candidate b. is harmonically bounded by a. Again, this conforms with the data presented in section 4.2 .

(19) N only

\begin{tabular}{|c|c|c|c|c|}
\hline & L & NUM $\Rightarrow \mathrm{R}$ & bounded by & Data \\
\hline a. B $\mathrm{V}>\mathrm{N}$ & & & - & 5 \\
\hline b. $\quad \mathrm{N}>\mathrm{V}$ & & * & a. & 1 \\
\hline
\end{tabular}

The second prediction is that in languages with fused agreement, i.e., agreement where NUM and PER agreement is always expressed by affixes marking both, the affixes should occur consistently prefixally or suffixally. This is true because the ranking in (20a) favors suffixes whereas the one in (20b) favors prefixes. No candidate is harmonically bounded by the other. 


\begin{tabular}{|c|c|c|c|}
\hline & L $\boldsymbol{\beta}$ PER & NUM $\Rightarrow \mathrm{R}$ & bounded by \\
\hline a. $B_{N U M} \mathrm{~V}>\mathrm{PN}$ & ** & & - \\
\hline b. BPER $\quad$ PN $>V$ & & $*$ & |- \\
\hline
\end{tabular}

Assuming that the ranking is essentially arbitrary for fused agreement marking, prefixes and suffixes should be distributed rather evenly in the languages of the world. This is confirmed empirically by Hawkins and Gilligans (1988: 225) who find that certain order preferences for other categories (suffixing over prefixing in certain contexts) do not hold for subject-person marking. In other words, there is no preference for prefixing or suffixing. Since most instances of "person marking" in their corpus are person-number marking, this is what we expect. Roughly, the same result is obtained from data presented in Julien (2000: 360): In 93 genera she finds that subject agreement is suffixal while it is prefixal in $85 .{ }^{10}$ In my data, fused person/number is prefixal in $30(42,3 \%)$ and suffixal in $41(57,7 \%)$ of 71 patterns. However, my data are not completely representative in this respect since certain types of agreement are over-represented in my sample (cf. section 3).

\subsection{Two Case Studies}

\subsubsection{Muna}

In Muna, the number affix -amu $[+\mathrm{pl}]$ follows the stem while the pure person markers $(o-[+2-1]$, no- $[+3])$ precede it (van den Berg 1989: 51):

$$
\begin{array}{llll}
\text { o-kala } & \text { o-kala-amu } & \text { no-kala } & \text { do-kala } \\
\text { S2-go } & \text { S2-go-PL } & \text { S3-go } & \text { S3p-go } \\
\text { 'you (sg.) go' } & \text { 'you (pl.) go' } & \text { 'he goes' } & \text { 'they go' }
\end{array}
$$

This follows from the assumed constraints under any ranking

$$
\text { o-kala-amu, 'you (pl.) go' }
$$

\begin{tabular}{|r||l|l|}
\hline & L $\bullet$ PER & NUM $\Rightarrow \mathrm{R}$ \\
\hline \hline $\mathrm{P}>\mathrm{V}>\mathrm{N}$ & & \\
\hline $\mathrm{P}>\mathrm{N}>\mathrm{V}$ & & $* !$ \\
\hline $\mathrm{V}>\mathrm{P}>\mathrm{N}$ & $* !$ & \\
\hline $\mathrm{N}>\mathrm{V}>\mathrm{P}$ & $* ! *$ & $* *$ \\
\hline
\end{tabular}


That the ranking is indeed $\mathrm{L} \diamond \mathrm{PER} \gg \mathrm{NUM} \Rightarrow \mathrm{R}$ and not the other way around can be seen from the fact that fused person/number markers ( $d o-$, $[+3+\mathrm{pl}])$, which are subject to both constraints, share the position of person, not the position of the number marker:

$$
\text { do-kala, 'they go' }
$$

\begin{tabular}{|l||l|l|}
\hline & L $\diamond$ PER & NUM $>\mathrm{R}$ \\
\hline \hline $\mathrm{PN}>\mathrm{V}$ & & $*$ \\
\hline $\mathrm{V}>\mathrm{PN}$ & $* !$ & \\
\hline
\end{tabular}

\subsubsection{Georgian}

shows the opposite ranking of L $<$ PER and NUM $\Rightarrow R$ as Muna. While pure person $(v-, 1$ st person $)$ and pure number agreement $(-t)$ also occur at the left and right edge (24) under this ranking, the 3pl marker -en (25) is on the right of the stem:

$$
v \text {-xedav- } t \text {, 'we see' }
$$

\begin{tabular}{|r||l|l|}
\hline & NUM $\Rightarrow \mathrm{R}$ & $\mathrm{L}$ く PER \\
\hline \hline $\mathrm{P}>\mathrm{V}>\mathrm{N}$ & & \\
\hline $\mathrm{P}>\mathrm{N}>\mathrm{V}$ & $* !$ & \\
\hline $\mathrm{V}>\mathrm{P}>\mathrm{N}$ & & $* !$ \\
\hline $\mathrm{N}>\mathrm{V}>\mathrm{P}$ & $* ! *$ & $* *$ \\
\hline
\end{tabular}

$(25)$

$$
\text { xedav-en, 'they see' }
$$

\begin{tabular}{|l||l|l|}
\hline & NUM $\Rightarrow \mathrm{R}$ & L $\diamond \mathrm{PER}$ \\
\hline \hline $\mathrm{PN}>\mathrm{V}$ & $* !$ & \\
\hline $\mathrm{V}>\mathrm{PN}$ & & $*$ \\
\hline
\end{tabular}

The case studies for Georgian and Muna show that the proposed alignment constraints do not just state crosslinguistic preferences, but - by their different rankings in single languages - result in complete accounts of particular grammars. They also illustrate that the effect of alignment cannot be reduced to the statement that person agreement precedes number agreement 
since this would not account for the behavior of fused person/number markers, which are positioned differently in different languages, but systematically within single languages. For the theory of grammar, replacing subcategorization frames of single affixes by general alignment constraints means eliminating a major source of language- and even morpheme-specific stipulation in favor of a formal device which is independently motivated by its usefulness to account for such different phenomena as infixation (Prince and Smolensky 1993), stress placement (McCarthy and Prince 1993), clitic ordering (Grimshaw 2000) and the alignment of syntactic and phonological phrases. According to the basic assumptions of OT (Prince and Smolensky 1993: 3), the constraint inventory forms the invariable core of universal grammar. Consequently, the proposed alignment constraints and their possible rankings also constitute a substantial theory of possible affix orderings making strong falsifiable predictions. The empirical claim of this approach is hence much stronger than that of functional approaches to affix order, which define only tendencies that cannot be vitiated by negative evidence from single languages. ${ }^{11}$ To maintain this restrictive account we must show that cases where person agreement apparently follows number agreement do not form real counterevidence against the assumed constraints. This is what I will try to do in the next section.

\subsection{Apparent Counterexamples}

Although the PER-NUM asymmetry seems to hold for a wide range of languages, there are counterexamples. I will show that these can be adduced to three factors: 1) Verbal plural markers that do not realize subject agreement but are incorporated quantifiers. 2) Affixes that encode other features than person and number, and 3) Affixes which are bound by their contextrestrictions to positions which violate alignment constraints.

The first case is exemplified in Jaqaru (Hardman 1966: 53), where the plural marker -rqay precedes person marking:

$$
\begin{aligned}
& \text { saynqu-rqay-k-i-wa } \quad \text { 'they all stand up' } \\
& \text { V-PL-TNS-3-TNS }
\end{aligned}
$$

However, Hardman notes that in Jaqaru "plurality is not an inflectional category" (p. 46). The plural marking both on nouns and verbs is "emphatic" (ibd.) and "the absence of the plural suffix does not imply singular" (p. 
53). Since "the usual translation is 'all' or 'everyone" "(ibd.), it is plausible that -rqay is an incorporated quantifier. Similar analyses seem to apply to apparent counterexamples in Navajo (Young and Morgan 1998) and Walapai (Redden 1966).

A second source of the order NUM $>$ PER is due to involvement of a third feature apart from person and number. Thus in Isthmus Zapotec (Pickett 1955: 221), person markers follow number markers, but person is generally fused with gender marking:

$$
\begin{aligned}
& \text { ru-Punda-ka-beé } \quad \text { 'they (an.) sing' } \\
& \text { HABIT-sing-PL- }[+3+\text { an }]
\end{aligned}
$$

While there are few cases of split gender agreement markers, in Semitic such markers exist and are usually suffixal. This suggests that there is a constraint GEND $\Rightarrow R$. If this is on the right track, it is plausible that GEND $\Rightarrow R$ also can induce violations of the PER-NUM asymmetry. Assuming that in Isthmus Zapotec GEND $\Rightarrow R$ is ranked over NUM $\Rightarrow R$, and that the prefix option for subject agreement is not available, we get the observed order:

$$
\text { Ranking of Isthmus Zapotec }
$$

\begin{tabular}{|r||l|l|l|}
\hline & GEND $\Rightarrow \mathrm{R}$ & $\mathrm{NUM}$ $\Rightarrow \mathrm{R}$ & $\mathrm{L}$ < PER \\
\hline \hline $\mathrm{V}[\mathrm{NUM}][\mathrm{PER}$ GEND $]$ & & $*$ & $* *$ \\
\hline $\mathrm{V}[\mathrm{PER}$ GEND $][\mathrm{NUM}]$ & $* !$ & & $*$ \\
\hline
\end{tabular}

A final source of counterexamples to the PER-NUM asymmetry are affixes that are bound to a certain position by a context restriction on the vocabulary item. One such case is the Ancash Quechua plural suffix -ya (Lakämper and Wunderlich 1998) which precedes all person marking (29).

However there is strong evidence that the offending order $\mathrm{N}>\mathrm{P}$ is induced by an idiosyncratic context-specification of the number affix and is not representative for the general positioning of number agreement in this language. Note first that $\mathrm{N}>\mathrm{P}$ only occurs in Ancash Quechua while the unmarked (opposite) order holds in Ayacucho Quechua. Even in Ancash, possessor agreement, which is otherwise completely parallel to intransitive subject agreement, number marking is taken over by another suffix (-kuna) which uniformly follows person markers and thus restates the expected order: 
Quechua Nominal and Verbal Agreement

\begin{tabular}{l||l|l|l|l|}
\multicolumn{4}{c||}{ Verbs } & \multicolumn{2}{c}{ Nouns } \\
& sg & pg & pl \\
\hline $\mathbf{1}$ & $-V$ & - ya- $V$ & $-V$ & $-V$-kuna \\
\hline $\mathbf{2}$ & $-n k i$ & -ya-nki & $-y k i$ & - yki-kuna \\
\hline $\mathbf{3}$ & $-n$ & - ya- $n$ & $-n$ & $-n-$ kuna \\
\hline $\mathbf{1 + 2}$ & & $-n t s i k$ & & $-n t$ sik \\
\hline
\end{tabular}

Finally, the 1st plural inclusive marker $-n t s i k[+\mathrm{PER}+\mathrm{NUM}]$ always occurs in final position if it marks object agreement and vacuously if it marks subject agreement. Again this shows the rightwards tendency of plural marking in this language.

In DO, the position of -ya can be accounted for by a context restriction such as $[+\mathrm{V}]$ - on its vocabulary item, which restricts it to the immediate right of a verbal item. Indeed, -ya seems always to occur right-adjacent to the stem or derivational markers ${ }^{12}$ which can be analyzed as light verbs (cf. Parker 1976). Lakämper and Wunderlich (1998) independently propose such a context restriction ${ }^{13}$ to account for the fact that $-y a$ cannot appear in nominal inflection (cf. (29)). Hence, the context restriction is necessary for independent reasons. The account with a context specification also explains the fact that other plural affixes in Ancash such as the nominal plural marker -kuna obey the alignment constraint on plural affixes. Under lexicon optimization (Prince and Smolensky 1993), such a context specification will lead to reanalysis whenever it is possible. This is confirmed by the fact that in three of four Quechua dialects discussed by Lakämper and Wunderlich (1998) - ya is abandoned in favor of a plural marker in the canonical order.

\section{The Order of Syntactic Heads}

Under the assumptions of DM, split agreement affixes are a result of morphological operations, while interpretable affixes such as Tense and Aspect normally have unique correspondents in syntax. The order of these affixes should therefore reflect syntactic principles, different from the ones regulating the order of split agreement. In this section, I show that this is indeed the case, following closely the analysis of Julien (2000). 
Julien shows that Aspect affixes appear closer to the stem than Tense affixes if both are suffixes or both are prefixes. However if the two types of markers appear on different sides of the verb stem, there are clear examples of the order Tense $>$ Verb $>$ Aspect while the reverse order, Aspect $>$ Verb $>$ Tense, is virtually non-existent. Schematically, we find the pattern in (30): ${ }^{14}$

\begin{tabular}{|l||l|l|l|}
\hline & both prefixes & Mixed & both suffixes \\
\hline \hline T $>$ A & Tense Aspect Verb & Tense Verb Aspect & *Verb Tense Aspect \\
\hline $\mathrm{A}>\mathrm{T}$ & *Aspect Tense Verb & *Aspect Verb Tense & Verb Aspect Tense \\
\hline
\end{tabular}

Hence, we find again an ordering restriction ( $\boldsymbol{\sim}$ Tense $>$ Verb $>$ Aspect but *Aspect $>$ Verb $>$ Tense) that cannot be captured by standard generative accounts of affix order which do not restrict the order of affixes on opposite sides of the verb.

Julien's account derives the restrictions depicted in (30) from the assumption of a universal phrase structure for functional categories and the independently motivated antisymmetric framework of Kayne (1994), where a universally uniform Specifier Head Complement structure and the restriction of movement to leftwards movement is assumed. Under this approach, there are four possible situations where Tense, Aspect, and Verb can become adjacent, and hence are analyzed as "words": In the base-generated order, all affixes stay in the positions where they are generated without movement. This gives the order Tense $>$ Aspect $>$ Verb:

The base-generated order

\section{Tense Aspect Verb}

If the verb head-moves up to $\mathrm{Asp}^{0}$, the order Verb $>$ Aspect $>$ Tense results: 
Head-Movement to Aspect

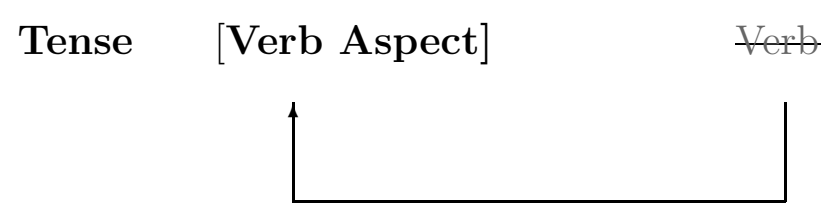

Further movement of the complex [Verb Aspect ] to Tense ${ }^{0}$ leads to a standard head-movement pattern:

(33) Further Movement to Tense

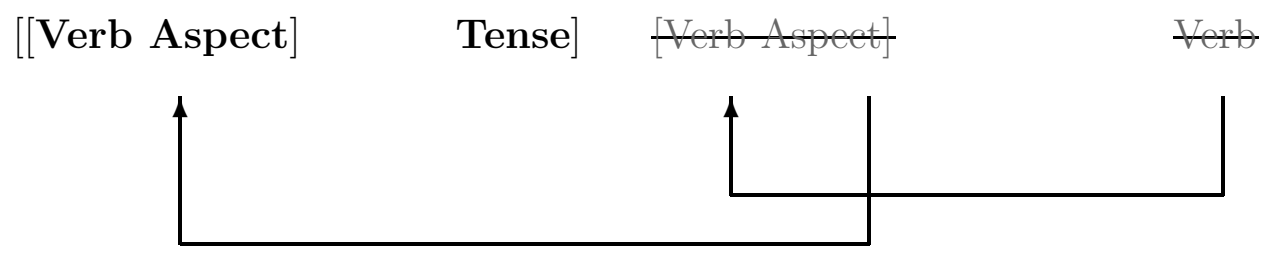

While these options suffice to derive the three occurring patterns, a fourth scenario is necessary to account for the frequent appearance of suffixes in verb-final languages, which can hardly be the result of moving the head to $\mathrm{V}$, resulting in a sentence-medial position of the verb. Julien (2000: chapter 4) shows convincingly that in this language type the dominant pattern is movement of the complements to the specifiers of functional heads. Thus, in (34) the VP - including all complements - has moved to the specifier of $\mathrm{Asp}^{0}$. Subsequently, the Aspect Phrase has moved to the specifier of TP:

(34) Phrasal Movement

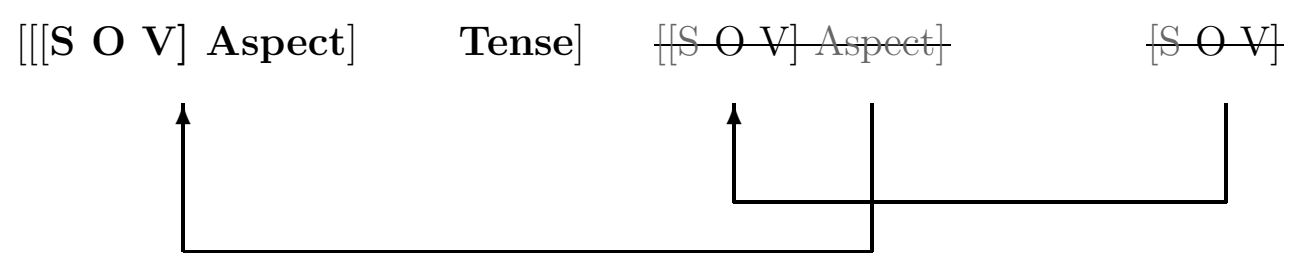

Note why it is not possible to extend this account to split agreement, where affixes are ordered according to the pattern in (35a) while Tense and Aspect reflect (35b): 


$$
\begin{aligned}
& \text { a. } \text { Prefix }_{\text {type } 1} \text { Prefix }_{\text {type } 2} \mathrm{~V} \Leftrightarrow \mathrm{V} \text { Suffix }_{\text {type } 1} \text { Suffix }_{\text {type2 }} \\
& \text { (type1 = PER, type2 = NUM) } \\
& \text { b. Prefix } \text { type } 1_{\text {Prefix }} \text { type } 2 \mathrm{~V} \Leftrightarrow \mathrm{V} \text { Suffix }_{\text {type } 2} \text { Suffix }_{\text {type } 1} \\
& \text { (type } 1=\text { Tense, type } 2=\text { Aspect) }
\end{aligned}
$$

This indicates strongly that agreement and syntactic heads as Tense and Aspect are subject to different principles. However, the antisymmetric and the alignment-based account are complementary in the sense that together they obviate the need for any idiosyncratic specifications whether a single affix is a prefix or a suffix. While this follows from the alignment constraints in the first case, in the latter it results directly from syntactic movement. Thus the fact that Tense is a prefix in (31) and (32), but a suffix in (33) and (34), results from the movement of the verb to the left of Tense in the latter but not in the former cases.

In the next two sections, I will investigate how a combination of the movement and the alignment approach can account for restrictions on the relative order of subject agreement and Tense affixes.

\section{The Interaction of Movement and Align- ment}

Up to this point, we have identified two grammar modules responsible for different ordering patterns. The basic question is now whether and how these modules interact. In this section, I will investigate this question on the basis of ordering restrictions on subject agreement and Tense inflection. I will assume that the interaction between morphology and syntax in this area is asymmetric: Morphological constraints cannot change the order of elements such as Aspect and Tense which is determined by syntax. However, the ordering of subject agreement is partially determined by syntactic constraints. Since agreement itself is not present in syntax, I attribute this to the fact that agreement is attached to a syntactic category at Chain Interpretation and to a constraint which requires that agreement "reflects" the position of its host at head interpretation. I will introduce several types of interaction between morphology and syntax and show how they can be accounted for under the proposed assumptions. In section 7, it will be shown that the same assumptions allow to derive the basic ordering generalizations for these markers that result from my language sample. 
The simplest conceivable type of interaction is no interaction at all. This can be observed in the Nilo-Saharan language Turkana (Dimmendaal 1983: $122,130)$, as evidenced in the following verb forms:

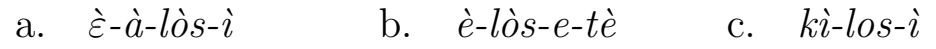

$$
\begin{aligned}
& \text { 3-Past-go-Asp 3-go-Asp-PL S1pl-go-Asp } \\
& \text { 'he went' 'they will go' 'we will go' }
\end{aligned}
$$

Tense $(\grave{a}$ - in $(36 \mathrm{a}))$ precedes the verb stem, while Aspect follows it (36a-c). This follows straightforwardly from movement of the verb to the Aspect head as in (32). The order of agreement affixes is completely parallel to the one for Muna (see section 4.4): Pure person marking ( $\dot{\varepsilon}-$ in $(36 a, b)$ ) and PER/NUM markers ( $k i$ - in $(36 \mathrm{c})$ ) precede all other markers, while the pure number marker (-tè in (36b)) follows all other affixes. Thus no interaction can be detected, but crucially Tense and Aspect seem to be part of the alignment domain for agreement. This excludes any account which posits the application of the morphological constraints in a presyntactic component of the grammar.

A more interesting type of interaction can be observed in Amharic (Leslau 1995: 287,301). In this language there are two basic verbal paradigms, the perfect and the imperfect. In the latter, agreement is again split and the order of affixes follows closely the one found in Muna and Turkana. Thus, Person and person/number affixes such as të- $[+2]$ or $\ddot{e} n n \ddot{e}-:[+1+\mathrm{pl}]$ precede the verb, while the plural suffix $-u$ follows it. However, in the perfect paradigm, all agreement markers are suffixes no matter what features they encode:

\begin{tabular}{l||l|l} 
& Imperfect & Perfect \\
\hline \hline 3. sg. mas & yë-säbër & säbbär-ä \\
\hline 3. sg. fem & të-säbër & säbbär-äcc \\
\hline 2. sg. mas & të-säbër & säbbär-h \\
\hline 2. sg. fem & të-säbr-i & säbbär-sh \\
\hline 1. sg. & $\ddot{e ̈-s a ̈ b e ̈ r ~}$ & säbbär-hu \\
\hline 3. pl. & yë-säbr-u & säbbär-u \\
\hline 2. pl. & të-säbr-u & säbbär-accuh \\
\hline 1. pl. & $\ddot{e ̈ n n e ̈-s a ̈ b e ̈ r ~}$ & säbbär-n \\
\hline
\end{tabular}

Even if we assume that all perfect markers encode person and number, this 
cannot be accounted for by invoking the introduced alignment constraints: L $\diamond$ PER favors prefixal agreement, and as is evidenced by the prefix ënnë$:[+1+\mathrm{pl}], \mathrm{L} \leftrightarrow \mathrm{PER}$ must be ranked above NUM $\Rightarrow \mathrm{R}$ in Amharic. But since there is a complete person differentiation in the perfect paradigm, agreement affixes must be marked for person.

The analysis I propose is based on the observation that the perfect paradigm is entirely determined by Tense/Aspect, while the position of Imperfect markers can be accounted for entirely by person- and number features. Note first that while Leslau uses the aspectual labels Perfect and Imperfect for these paradigms, his description of their uses (Leslau 1995: 291,311) implies that the "imperfect" rather conveys a present tense and the perfect a past tense interpretation. Indeed, Cowley et al. (1976: 86) treat these paradigms as different tenses. Now it is common for languages that present tense remains unexpressed by affixes while past tense is expressed by separate affixes or portmanteau affixes, as in the following examples from Georgian, where past tense is expressed by the marker $-n$ or the past/3sg affix $-a$ while there are no special affixes for present tense:
a. xedavd-en
'they see'
see-TENSE-S3p
b. xedavd-n-en
'they saw'
see-TENSE-S3p
c. $\quad x e d a v-s$
'he sees'
d. xedavd-a
'he saw'
see-TENSE:S3s

Since in Amharic there is no other affixal reflex of Aspect/Tense, it is plausible that the perfect affixes are actually portmanteau markers which encode past tense and agreement while the imperfective affixes are just agreement (the unmarked Tense/Aspect is not overtly realized). ${ }^{15}$ Assuming that the verb moves to Aspect/Tense, an affix realizing past should appear as a suffix. Following the assumption that order restrictions established by the syntax cannot be changed by morphological constraints, markers encoding agreement and Tense must reflect the underlying position of the latter, and this is exactly what we find in Amharic.

A third type of interaction can be found in Island Kiwai (Wurm 1975), where we find again a split of ordering of agreement categories in different 
tenses, but this time without fusion of Tense and subject agreement. In the present and past paradigms person markers are initial and number markers (here: dual) final: ${ }^{16}$

$$
\begin{array}{ccc}
\text { Present } & \text { Near Past } & \text { Definite Past } \\
n-V \text {-duru-do } & n-V-d o & n-V-r u-d o \\
1-\mathrm{V}-\mathrm{Tnn}-\mathrm{Du} & 1-\mathrm{V}-\mathrm{Du} & 1-\mathrm{V}-\mathrm{Tns}-\mathrm{Du}
\end{array}
$$

However, in the future tenses, the dual marker is realized as a prefix following a prefixal Tense marker:

(40) Indefinite Future Immediate Future

$$
\begin{array}{cc}
n i-d u-d o-V-r i & n i-d o-V-r i \\
1-T n s-D u-V-T n s & 1-D u-V-T n s
\end{array}
$$

If we make the plausible assumptions that all present and past forms have at least one TAM head, and all future forms at least two ${ }^{17}$, these forms can be given the structures in (41) and (42):

(41) Kiwai 1st dual form: Present/Past

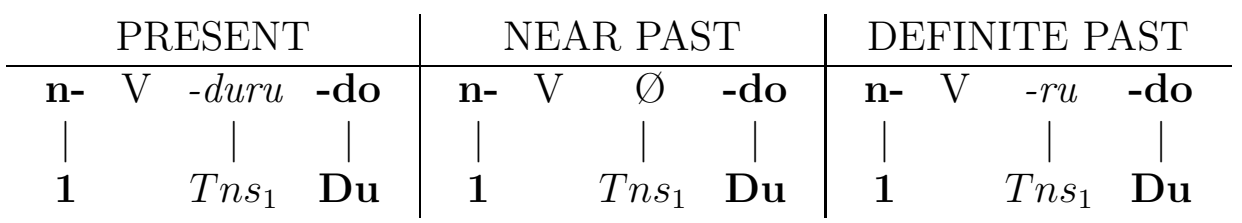

(42) Kiwai 1st dual forms: Future

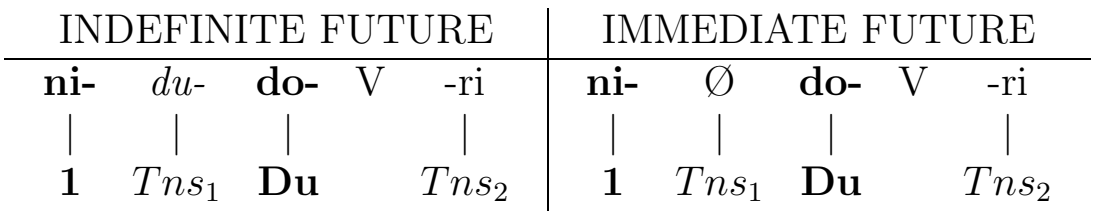

In an intuitive sense, the dual marker simply follows a certain Tense marker. I suggest to capture this intuition by the following constraint:

(43) REFLECT(AGR): An affix realizing an agreement category $A$ should reflect the position of its host $H$ by

a. being right-adjacent to an affix realizing $H$, or by

b. occupying the position of $H$, if $H$ is not realized 
If we assume that agreement is attached in Island Kiwai to Tense ${ }_{1}{ }^{18}$, this constraint will now interact with the already introduced alignment constraints to give the correct order for all affixes:

(44) Input: $\mathrm{V}[+ \text { Tense }]_{1}[+1+\mathrm{du}]($ PRESENT)

\begin{tabular}{|r||l|l|l|}
\hline & L $\diamond$ PER & REFLECT & NUM $\boldsymbol{~ R ~}$ \\
\hline \hline n-V-duru-do & & & \\
\hline $\mathbf{n}-$ do-V-duru & & $* !$ & $* *$ \\
\hline V-duru-n-do & $* !^{*}$ & & \\
\hline do-V-duru-n & $* !^{* *}$ & & $* * *$ \\
\hline
\end{tabular}

(45) Input: $[+ \text { Tense }]_{1}[+1+\mathrm{du}] \mathrm{V}[+ \text { Tense }]_{2}$ (INDEF.FUT)

\begin{tabular}{|r||l|l|l|}
\hline & L $\bullet$ PER & REFLECT & NUM ` R \\
\hline \hline ni- $d u$-do-V-ri & & & $* *$ \\
\hline ni-do- $d u$-V-ri & & $* !$ & $* * *$ \\
\hline$d u$-ni-do-V-ri & $* !$ & & $* *$ \\
\hline ni- $d u$-V-ri-do & & $* !$ & $* *$ \\
\hline
\end{tabular}

Assume now a hypothetical language $L$, where syntactic constraints on the positioning of Tense are out-ranked by morphological constraints, hence irrelevant. $L$ contains a person marker $\mathrm{P}$, a person/number marker $\mathrm{PN}$ and a Tense marker T. For the ranking REFLECT(AGR) $\gg$ NUM $\Rightarrow R \gg L$ $\mathrm{PER}$, we get the following results. In a form where only $\mathrm{P}$ appears, $\mathrm{P}$ and $\mathrm{T}$ are prefixes due to the irrelevance of NUM $\Rightarrow R$ :

(46) Influence of morphological constraints on Tense

\begin{tabular}{|r||l|l|l|}
\hline & REFLECT & NUM \& R & L ↔ PER \\
\hline \hline P T V & $* !$ & & \\
\hline T P V & & & $*$ \\
\hline V T P & & & $* * !$ \\
\hline V P T & $* !$ & & $*$ \\
\hline
\end{tabular}

However in a form with PN, NUM $\Rightarrow R$ comes crucial and "drags" T into the suffixal positions where NUM $\Rightarrow \mathrm{R}$ and REFLECT can be satisfied: 


\begin{tabular}{|r||l|l|l|}
\hline & REFLECT & NUM $\Rightarrow$ R & L $\bullet$ PER \\
\hline \hline PN T V & $* !$ & $* *$ & \\
\hline T PN V & & $* !$ & $*$ \\
\hline V T PN & & & $* *$ \\
\hline V PN T & $* !$ & $*$ & $*$ \\
\hline
\end{tabular}

$L$ is thus the mirror image of Island Kiwai: While in Kiwai different Tense heads with different positions induce different positions of one and the same agreement affixes, in $L$ different agreement affixes would enforce different positions of one and the same Tense affix.

I hypothesize that such a language is impossible, but if this is true further research has to reveal why exactly this is the case. Since affix order in DO as well as in DM is determined after syntax, this does not directly follow from the derivational priority of syntax. However the priority of syntax over morphology seems also to hold in other domains such as verb movement (Bobaljik 2001) and feature neutralization (Trommer 2002b).

\section{The Relative Order of SAgr and Tense}

REFLECT(AGR) and the fact that subject agreement tends to adjoin syntactically to Tense (Halle and Marantz 1993: 146) ${ }^{19}$ let us expect that there should be a preference for Tense and agreement occurring on the same side of the stem because there are more possible rankings that favor "conformity" of Tense and SAgr than rankings disfavoring it:

(48) Tense suffix

\begin{tabular}{|l||l|l|}
\hline & Ranking & Affixal Status \\
\hline \hline $\mathrm{V}>\mathrm{T}>\mathrm{A}$ & REFLECT AGR $\gg \ldots$ & conform \\
\hline $\mathrm{V}>\mathrm{T}>\mathrm{A}$ & $\mathrm{NUM} \boldsymbol{\mathrm { R }} \gg \ldots$ & conform \\
\hline $\mathrm{A}>\mathrm{V}>\mathrm{T}$ & $\mathrm{L} \boldsymbol{\bullet} \mathrm{PER} \gg \ldots$ & not conform \\
\hline
\end{tabular}




\begin{tabular}{|ll||l|l|}
\hline & & Ranking & Affixal status \\
\hline \hline $\mathrm{T}>\mathrm{A}>\mathrm{V}$ & REFLECT AGR $\gg \ldots$ & conform \\
\hline $\mathrm{A}>\mathrm{T}>\mathrm{V}$ & $\mathrm{L} \diamond \mathrm{PER} \gg \ldots$ & conform \\
\hline $\mathrm{T}>\mathrm{V}>\mathrm{A}$ & $\mathrm{NUM} \gg \mathrm{R} \gg \ldots$ & not conform \\
\hline
\end{tabular}

Indeed, in a majority of languages if Tense and agreement affixes cooccur, the agreement affix has the same affixal status as the Tense affix. (50) and (51) show the relevant results from my sample and Julien (2000):

(50) Affixal status of SAgr and Tense (my sample)

\begin{tabular}{|l|ll|ll|ll|}
\hline & \multicolumn{2}{|c|}{ T suffix } & \multicolumn{2}{|c|}{ T prefix } & \multicolumn{2}{c|}{ all } \\
\hline \hline Agr conform & 48 & $71.6 \%$ & 19 & $70.4 \%$ & 67 & $71.3 \%$ \\
\hline Agr not conform & 19 & $28.4 \%$ & 8 & $29.6 \%$ & 27 & $28.7 \%$ \\
\hline sum & 67 & & 27 & & 94 & \\
\hline
\end{tabular}

Affixal status of SAgr and Tense (Julien 2000: 360)

\begin{tabular}{|l|ll|ll|ll|}
\hline & \multicolumn{2}{|c|}{ T suffix } & \multicolumn{2}{c|}{ T prefix } & \multicolumn{2}{c|}{ all } \\
\hline \hline Agr conform & 80 & $58.4 \%$ & 23 & $71.9 \%$ & 103 & $60.9 \%$ \\
\hline Agr not conform & 57 & $41.6 \%$ & 9 & $28.1 \%$ & 66 & $39.1 \%$ \\
\hline sum & 137 & & 32 & & 169 & \\
\hline
\end{tabular}

In the following, I will discuss in more detail the possible positions of Tense and SAgr and show that the assumed constraint set makes the correct predictions for the found ordering preferences. Since my sample is somewhat biased for the reasons discussed in section 3, I will use in addition the results from Julien (2000). Note that the references to agreement in the following refer to all instances of agreement in my sample (person, number, or person and number fused).

\subsection{SAgr and Tense as Prefixes}

Assume first that both SAgr and Tense are prefixes. In my sample, there is a slight preference $(\approx 60 \% / 40 \%$ for the order Tense $>$ Agreement) while in Julien's evaluation it is the other way around. Since in this constellation 
Julien's and my results differ, I have additionally evaluated the affix order data she gives in the appendix of her thesis (third column). Here, there is a roughly even distribution of both orders. Probably this divergence is due to the fact that her criteria to set apart agreement markers from pronouns — which exclude many cases of agreement in polysynthetic languages — are not reflected in her raw data.

(52) Order of SAgr and Tense as Prefixes

\begin{tabular}{|l|ll|ll|ll|}
\hline & my results & \multicolumn{2}{|l|}{ Julien's results } & \multicolumn{2}{l|}{ Julien's data (appendix) } \\
\hline \hline $\mathrm{T}>\mathrm{A}$ & 15 & $62.5 \%$ & 9 & $39.1 \%$ & 17 & $47.2 \%$ \\
\hline $\mathrm{A}>\mathrm{T}$ & 9 & $37.5 \%$ & 14 & $60.9 \%$ & 19 & $52.8 \%$ \\
\hline sum & 24 & & 23 & & 36 & \\
\hline
\end{tabular}

Taken together, I interpret these data as evidence that there is no crosslinguistic evidence for an order preference for Tense/Agreement in prefixal position. This is exactly what is expected given the assumed constraints. Since the order Tense $>$ Verb is given by syntax, there are three possible orders at Head Interpretation: SAgr $>$ Tense $>$ Verb, Tense $>$ SAgr $>$ Verb and Tense $>$ Verb $>$ SAgr. The last order results from a high ranked NUM $\Rightarrow$ $\mathrm{R}$ and will be discussed in section 7.3. If REFLECT(AGR) is crucially undominated, SAgr must appear rightadjacent to Tense; hence we get: Tense $>$ SAgr $>$ Verb. SAgr $>$ Tense $>$ Verb emerges if L $\$$ PER dominates all other crucial constraints since this is the only prefixal order where this constraint is unviolated. Putting it in another way: Given Tense $>\mathrm{V}$ there are two relevant constraints that favor prefixal Tense/SAgr. One favors the order Tense $>$ SAgr and the other SAgr $>$ Tense. If ranking is assumed to be arbitrary, this should result in an even crosslinguistic distribution of the two orders, and this is what is borne out by the data.

\subsection{SAgr and Tense as suffixes}

While the ordering possibilities of SAgr and Tense as prefixes are rather symmetric, there is a clear asymmetry in suffixal position. Verb $>$ Tense $>$ SAgr overwhelmingly outranks Verb > SAgr > Tense: 


\begin{tabular}{|l|ll|ll|}
\hline & \multicolumn{2}{|c|}{ my results } & \multicolumn{2}{|c|}{ Julien's data } \\
\hline \hline $\mathrm{T}>\mathrm{A}$ & 44 & $84.6 \%$ & 64 & $80 \%$ \\
\hline $\mathrm{A}>\mathrm{T}$ & 8 & $15.4 \%$ & 16 & $20 \%$ \\
\hline sum & 52 & & 80 & \\
\hline
\end{tabular}

This is again predicted by the assumed set of constraints. Assume that Tense is a suffix. High ranking of L $\bullet$ PER will lead to prefixal agreement (see section 7.3). But if either REFLECT(AGR) or NUM $\Rightarrow R$ are crucially undominated, this will result in Verb $>$ Tense $>$ SAgr since the rightmost position and the position right-adjacent to Tense coincide. Crucially, there is no constraint that would favor the order Verb $>$ SAgr $>$ Tense.

What remains problematic then is the fact that there are instances of the order Verb $>$ SAgr $>$ Tense at all. Some of these cases - at least in my sample - are due to special properties of single affixes. Thus, the Quechua plural affix was argued to have the context restriction $/[+\mathrm{V}]$ - in section 4.5 and therefore always precedes Tense. A second class of exceptions are languages with the order: Verb $>\mathrm{SAgr}_{1}>\mathrm{T}>\mathrm{SAgr}_{2}$. An example is Dumi:

$$
\begin{aligned}
& \text { phik } k \dot{k}-t-a \\
& \text { get:up- }[+1+\text { pl]-NPast-[-du] 'we (exc.) get up' (p. 96) }
\end{aligned}
$$

Note that the offending $-k A$ only appears together with a second number affix that appears after the Tense marker. In Trommer (2002a) this is related to a constraint that allows only one agreement affix in a post-tense position. If this outranks REFLECT and NUM $\Rightarrow \mathrm{R} \gg \mathrm{L} \backsim \mathrm{PER}$, this leads to the observed order. Finally, there seem to be languages where SAgr is adjoined to a non-tense head. ${ }^{20}$ in which case REFLECT(AGR) is predicted to reflect the position of its "alternative" host, not of Tense.

\subsection{SAgr and Tense on different Sides of the Stem}

Siewierska (1993: 68) makes the observation that

$$
\text { "... if SAgr is a suffix so is the Tense marker." }
$$

Siewierska finds that this is true for $91 \%$ of the languages from a sample of 262 languages. These results are also replicated in other studies 


\begin{tabular}{|l|ll|ll|ll|}
\hline & \multicolumn{2}{|l|}{ Siewierska (1993) } & \multicolumn{2}{|l|}{ Julien (2000) } & my sample \\
\hline \hline $\mathrm{A}>\mathrm{V}>\mathrm{T}$ & 68 & $88.3 \%$ & 57 & $86.4 \%$ & 19 & $70.4 \%$ \\
\hline $\mathrm{T}>\mathrm{V}>\mathrm{A}$ & 9 & $11.7 \%$ & 9 & $13.6 \%$ & 8 & $29.6 \%$ \\
\hline sum & 77 & & 66 & & 27 & \\
\hline
\end{tabular}

This result seems to be problematic, since, according to the proposed constraints, SAgr $>$ Verb $>$ Tense given suffixal Tense and Tense $>$ Verb $>$ SAgr given prefixal Tense are equally probable. In each case, alignment constraints can be said to outrank REFLECT.

The point however is that suffixal Tense is much more frequent than prefixal one (Julien 2000: 51 ff.). Especially in the patterns involving Tense and SAgr, suffixal Tense is far more frequent. This is true in my data for 75 of 107 patterns (70\%) and for Julien's data in 127 out of $172(79.6 \%)$

$$
\text { Affixal status of SAgr and Tense (Mixed) }
$$

\begin{tabular}{|l|ll|ll|}
\hline & my results & \multicolumn{2}{|l|}{ Julien's data } \\
\hline \hline $\mathrm{T}>\mathrm{A}$ & 44 & $84.6 \%$ & 64 & $80 \%$ \\
\hline $\mathrm{A}>\mathrm{T}$ & 8 & $15.4 \%$ & 16 & $20 \%$ \\
\hline sum & 52 & & 80 & \\
\hline
\end{tabular}

The distribution of Tense and SAgr in the mixed cases thus seems to follow crucially from the independent distribution of Tense alone. ${ }^{21}$

\section{Word order and the position of agreement}

An important part of the literature on affix order (e.g. Cutler et al. 1985, Bybee et al. 1990, Siewierska and Bakker 1996) tries to relate the position of affixes with respect to stems to the basic constituent order of the respective languages. Certainly any account of affix order should be at least consistent with the basic findings in this line of research. Siewierska and Bakker (1996: 144) give an overview of the results of research on the relation between basic word order types and the position of subject agreement markers in different language samples (S \& B = Siewierska and Bakker 1996, H \& G = Hawkins and Gilligan, B \& $\mathrm{P}=$ Bybee and Perkins, the latter two samples and the Stassen sample are documented in Hawkins and Gilligan 1988). ${ }^{22}$ 
(58) The form of SAgr affixes relative to basic order

(Siewierska and Bakker 1996: 144)

\begin{tabular}{cccc}
\hline sample & suffix & prefix & both \\
\hline
\end{tabular}

\section{V3}

$\begin{array}{llrrrrrr}\text { S \& B } & \mathrm{N}=80 & 43 & 54 \% & 27 & 34 \% & 10 & 12 \% \\ \text { Stassen } & \mathrm{N}=35 & 24 & 69 \% & 8 & 23 \% & 3 & 9 \% \\ \text { H \& G } & \mathrm{N}=16 & 12 & 75 \% & 3 & 19 \% & 1 & 6 \% \\ \text { B \& P } & \mathrm{N}=9 & 4 & 44 \% & 4 & 44 \% & 1 & 12 \%\end{array}$

\section{$\mathrm{V} 2$}

$\begin{array}{llrrrrrr}\text { S \& B } & \mathrm{N}=38 & 11 & 29 \% & 21 & 34 \% & 6 & 16 \% \\ \text { Stassen } & \mathrm{N}=22 & 8 & 36 \% & 11 & 23 \% & 3 & 14 \% \\ \text { H \& G } & \mathrm{N}=12 & 5 & 42 \% & 5 & 19 \% & 2 & 16 \% \\ \text { B \& P } & \mathrm{N}=4 & 1 & 25 \% & 2 & 44 \% & 1 & 25 \%\end{array}$

\section{V1}

\begin{tabular}{lllllllr} 
S \& B & $\mathrm{N}=15$ & 7 & $47 \%$ & 6 & $40 \%$ & 2 & $13 \%$ \\
Stassen & $\mathrm{N}=7$ & 4 & $57 \%$ & 3 & $43 \%$ & - & - \\
$\mathrm{H} \& \mathrm{G}$ & $\mathrm{N}=10$ & 3 & $30 \%$ & 6 & $60 \%$ & 1 & $10 \%$ \\
$\mathrm{~B} \& \mathrm{P}$ & $\mathrm{N}=5$ & 1 & $20 \%$ & 4 & $80 \%$ & - & - \\
\hline
\end{tabular}

The results for V1 and V2 languages are rather contradictory. However, there seems to be a robust trend for agreement affixes in V-final languages to be suffixal. ${ }^{23}$ This trend is also corrobated by the data from Julien (2000): ${ }^{24}$

(59) Position of Agreement markers relative to word order (Julien 2000: 360)

\begin{tabular}{|l||c|c|}
\hline & preposed & postposed \\
\hline \hline V-initial & 15 & 15 \\
\hline V-medial & 62 & 24 \\
\hline V-final & 48 & 73 \\
\hline Uncertain & 34 & 127 \\
\hline
\end{tabular}

In the proposed account there is clearly no direct connection between the position of subject agreement and word order. However there is an indirect link between the two since agreement is assumed to be attached to Tense, 
which in turn is ordered by syntactic operations. Thus Tense should work as a type of transmission belt, which mediates the relation of word order and subject agreement. To test this hypothesis, we first have to look at the relation of the position of Tense and basic word order (Julien 2000). (60) shows the percentages of $\mathrm{V}$-initial, $\mathrm{V}$-medial and $\mathrm{V}$-final languages which have prefixal $(\mathrm{T}>\mathrm{V})$ and suffixal $(\mathrm{V}>\mathrm{T})$ Tense markers. ${ }^{25}$

(60) Position of Tense markers relative to word order (Julien 2000: 339)

\begin{tabular}{|l||rr|rr|r|}
\hline \multicolumn{1}{|c||}{} & \multicolumn{2}{c|}{$\mathrm{T}>\mathrm{V}$} & \multicolumn{2}{c|}{$\mathrm{V}>\mathrm{T}$} & genera \\
\hline \hline V-initial & 24 & $67 \%$ & 19 & $51 \%$ & 36 \\
\hline V-medial & 66 & $65 \%$ & 67 & $66 \%$ & 101 \\
\hline V-final & 34 & $25 \%$ & 127 & $92 \%$ & 138 \\
\hline
\end{tabular}

From these data it seems that there is a strong preference for suffixing in V-final languages while both suffixes and prefixes are well-represented in verb-initial and SVO languages. Again data from different samples show considerable variation:

(61) The form of Tense affixes relative to basic order (Hawkins and Gilligan 1988)

\begin{tabular}{llrrrrrr}
\hline \multicolumn{2}{c}{ sample } & \multicolumn{1}{c}{ suffix } & \multicolumn{1}{c}{ prefix } & \multicolumn{1}{c}{ both } \\
\hline V3 & & & & & & & \\
Stassen & $\mathrm{N}=35$ & 31 & $88.6 \%$ & 2 & $5.7 \%$ & 2 & $5.7 \%$ \\
H \& G & $\mathrm{N}=15$ & 15 & $100 \%$ & 0 & $0 \%$ & 0 & $0 \%$ \\
B \& P & $\mathrm{N}=14$ & 14 & $100 \%$ & 0 & $0 \%$ & 0 & $0 \%$ \\
& & & & & & & \\
V2 & & & & & & & \\
Stassen & $\mathrm{N}=22$ & 14 & $63.6 \%$ & 5 & $22.7 \%$ & 3 & $13.6 \%$ \\
H \& G & $\mathrm{N}=10$ & 5 & $50 \%$ & 4 & $40 \%$ & 1 & $10 \%$ \\
B \& P & $\mathrm{N}=2$ & 0 & $0 \%$ & 2 & $100 \%$ & 0 & $0 \%$ \\
& & & & & & & \\
V1 & & & & & & & \\
Stassen & $\mathrm{N}=6$ & 4 & $66.7 \%$ & 1 & $16.7 \%$ & 1 & $16.7 \%$ \\
H \& G & $\mathrm{N}=10$ & 1 & $10 \%$ & 4 & $40 \%$ & 0 & $0 \%$ \\
B \& P & $\mathrm{N}=3$ & 1 & $33.4 \%$ & 2 & $66.6 \%$ & 0 & $0 \%$ \\
\hline
\end{tabular}


While for SVO and VOS languages there is a rather diffuse picture, prefixation being preferred in some and suffixation preferred in other samples, there is a constant preference for suffixing in OV languages. This contrast between VO and OV languages can be accounted for if we assume with Julien (2000) that verb-final languages typically result from the movement of complements to specifiers, as in (34), while VO languages result from a much wider variety of syntactic configurations. Now let us assume in a simplifying manner that Tense in $(\mathrm{S}) \mathrm{V}(\mathrm{S}) \mathrm{O}$ languages is equally often prefixal and suffixal, while it is more often suffixal in SOV languages. Recall that the alignment constraints for person and number as a whole do not favor suffixes or prefixes since they act as antagonists. However, COHERENCE lets us expect that agreement should at least tend to occur at the same side of the verb as Tense. This is clearly borne out for agreement in SOV languages. In SVO/VSO languages we would expect no preference at all for suffixing or prefixing since there is also no such preference for Tense and the alignment constraints are neutral in this respect. Given the contradictory tendencies for different samples, this also seems to be a reasonable result.

\section{Alternative Approaches}

Standard generative accounts to affix order (e.g. Baker 1985, Halle and Marantz 1993, Wunderlich 1996) - while differing considerably in basic assumptions and details - assume that generalizations on affix orders exhibit a mirror image, i.e., if we find the standard order Prefix $x_{\text {Type } 1}$ Prefix ${ }_{\text {Type } 2}$ Stem (where the indices Type1 and Type2 stand for affix types such as person agreement, Tense etc.) this implies the standard order Stem Suffix $x_{\text {Type } 2}$ Suffix $x_{\text {Type1 }}$. Moreover, it is assumed that the status of affixes as prefixes or suffixes is largely arbitrary, determined by affix-specific stipulation in lexical entries. Thus we expect for person and number something like (62):

\begin{tabular}{|l||l|l|l|}
\hline & both prefixes & Mixed & both suffixes \\
\hline \hline P $>$ N & *Person Number V & Person V Number & V Person Number \\
\hline N $>$ P & Number Person V & Number V Person & *V Number Person \\
\hline
\end{tabular}

But for person and number affixes, the data from my sample reveal a completely different picture. First, the order of these categories tends to be 
Person $>$ Number, no matter whether both are prefixes or both are suffixes. And second, the order of affixes on different sides of a verb is restricted $(\boldsymbol{\sim}$ PER V NUM, but not *NUM V PER), and this seems to be even the strongest ordering restriction that can be observed for person and number agreement. Thus we find roughly the distribution in (63):

\begin{tabular}{|l||l|l|l|}
\hline & both prefixes & Mixed & both suffixes \\
\hline \hline $\mathrm{P}>\mathrm{N}$ & Person Number V & Person V Number & V Person Number \\
\hline $\mathrm{N}>\mathrm{P}$ & *Number Person V & *Number V Person & *V Number Person \\
\hline
\end{tabular}

Moreover, standard generative accounts have no explanation why there should be an ordering asymmetry for fused Person/Number with respect to simple Person and Number markers.

The situation is slightly different for antisymmetric accounts of affix order (Kayne 1994, Cinque 1999, Julien 2000) which do predict an asymmetry between prefixes and suffixes. Such an account was argued to be correct for Tense and Aspect affixes in section 5. But also for subject agreement this approach would incorrectly predict that the ordering preferences for prefixes should mirror those of suffixes.

The "diachronic syntax hypothesis" offers a completely different approach to affixal status ${ }^{26}$ assuming that the position of affixes with respect to stems shows "a preference for morphemes to be located in the positions of the separate words which gave rise to them." (Siewierska and Bakker 1996: 145). In other words, agreement markers which develop from pronouns (or auxiliaries) in post-verbal position tend to become suffixes, and pronouns/auxiliaries in preverbal position tend to grammaticalize into prefixes. While the historical development of agreement affixes might ultimately be an important factor in a full understanding of the PER-NUM asymmetry, it offers no perspective on an adequate synchronic representation of affix position. Moreover, we have only few possibilities of historical reconstruction for languages which show such a split in their agreement patterns. The only reconstructions for verbal number agreement markers I am aware of are Mithun (1991) for some American Indian languages, and Frajzyngier (1997) for Chadic. ${ }^{27}$ In both cases the plural markers seem to have developed from demonstratives and/or personal pronouns (which themselves often grammaticalize from demonstratives, cf. Lehmann 1995: 37). However, tracing back markers of number 
agreement to pronouns teaches us nothing about the asymmetry between person and number markers since person markers also derive in the standard case from pronouns (Lehmann 1995: 41). In other words, if both types of markers derive from the same sources and their position is determined by their syntactic origins, they should have the same positional properties. However, there might be different historical sources for number agreement markers, such as plural words (Dryer 1989), verbal pluractionality markers (Durie 1986, Corbett 2000: chapter 8), distributivity and collective markers or numerals (especially in the case of dual markers).

Interestingly, distributivity and collective markers seem to have rather different positional properties than verbal agreement markers. Thus, Navajo has a distributive prefix $i$ - which precedes person (and number) marking (Young and Morgan 1998: 62). Similar facts can be observed for Walapai (Trommer 2002a: 151), and also the Jaqaru data discussed in section 4.5 show that quantificational elements which are a potential historical source for number agreement markers do not show the order with respect to person affixes which we expect for number agreement. If "real" number agreement has developed from such markers its positional properties must be the result of other factors than merely the position of its grammaticalization source. But even if the preference of number agreement for suffixal position could be traced back to its grammaticalization sources without problems, this would not provide an account for the relative position of person and number which appear on the same side of the verb.

Siewierska and Bakker (1996) also point to a more general problem with this type of approach. They observe that object agreement markers tend to follow subject agreement markers no matter on which side of the verbal stem both occur. However, even though Siewierska and Bakker are generally sympathetic to the diachronic syntax approach, they admit that it is not of much use in accounting for ordering patterns of this type since "in view of the fact that SAgr and OAgr need not evolve simultaneously, one would not expect there to be any evident parallels between the order of the subject and object at clause level and the order of SAgr and OAgr affixes" (Siewierska and Bakker 1996: 149). This argument also carries over to a putative diachronic account of the PER-NUM asymmetry: There is no reason to believe that person and number agreement markers have become affixal at the same time, hence no systematic relation between their positions is to be expected.

While the work cited up to this point focuses on affixal status, Bybee (1985) provides an account for the relative positions of affixes on the same 
side of the stem. She argues that the proximity of affixes to the verbal stem is determined by the relevance of the semantic information of the affix to the verbal semantics. According to this account, number agreement should tend to appear closer to the stem than person agreement. This leads to roughly the same empirical predictions as for standard generative accounts which seem to be empirically incorrect for agreement morphology.

Cutler et al. (1985) advocate a processing-based approach which also addresses the question of affixal status. They assume that this is governed by a general suffixing preference and the tendency of affixes to obey the Head Ordering Principle (HOP), which requires that heads (e.g. the verb in a verb phrase or an inflectional affix in a word) in a given language consistently follow or precede their complements. This approach is problematic since subject agreement does not seem to have a crosslinguistic preference for either suffixal or prefixal status, and more generally, because different affix types (Tense, Aspect, agreement, etc.) show different positional preferences (see also Julien 2000, Siewierska and Bakker 1996 for further critical discussion).

What is appealing about the accounts of Bybee (1985) and Cutler et al. (1985) is that they try to give a functional motivation of affix ordering principles. Could there be a similar argument for grounding the alignment constraints proposed in this paper? Psycholinguistic evidence shows that the positions which are targeted by these constraints are the two most prominent positions for word recognition: the word initial position is the most crucial one while "endings are more salient than middles" (Cutler et al. 1985: 743). That person and number are aligned roughly to these positions could be seen as a strategy to maximize the recoverability of agreement features in language comprehension. In a different way, REFLECT also enhances recoverability, since it facilitates the reconstruction of the underlying morphosyntactic process, i.e., of the attachment of agreement, to Tense. That person is aligned to the more prominent position could be related to a more general prominence of person over number. Thus, Noyer (1992) finds that in different morphological processes (e.g. affix choice for templatic positions) person features have priority over number features and Corbett (2000: 278) states that in paradigms of pronouns and agreement affixes "number usually depends on person, but person may depend on number". ${ }^{28}$ Data from Siewierska and Bakker (1996: 122) show that for their language sample pure person agreement markers are significantly more frequent $(21=11.7 \%$ of 180 markers) than pure number markers $(12=6.7 \%$ of 180 markers $)$ and also that languages with person agreement (93\% of 237 ) are slightly more frequent 
than those with number agreement ( $88 \%$ of 237$).{ }^{29}$ While these remarks are highly speculative, it seems plausible that the account in terms of alignment constraints is not only empirically superior to alternative approaches, but can also be motivated on functional grounds.

\section{Summary}

In this paper I have shown that the interaction of morphology and syntax in an OT grammar accounts for a wide range of facts about the order of subject agreement affixes, both crosslinguistically and in the grammar of single languages. It remains to be seen how this type of account extends to other affix types. Trommer (2002a) shows that the ordering of fused subject/object agreement also follows an alignment pattern and discusses some tentative results on object agreement pointing in the same direction. Hyman (2001) shows that affixes involved in Bantu grammatical-function changing processes (causative, passive, etc.) also show the interplay of syntactic/semantic constraints with purely morphological factors. ${ }^{30}$ Interestingly, there is independent morphological evidence that at least voice affixes form a natural class with agreement and are inserted "late" after syntax (Embick 1998). This gives further support to the claim that the asymmetry between Tense/Aspect and Agreement is due to the more principled difference between syntactic and morphological affixes.

\section{Appendix: The Language Survey}

The following table lists the languages from my language sample. The second column contains the phyla according to Ruhlen (1987), the third column the linguistic macro-area according to Dryer (1992), and the fourth column the source of the data: ${ }^{31}$

$\begin{array}{llll}\text { Language } & \text { Phylum } & \text { Macro-Areas } & \text { Source } \\ \text { Acoma } & \text { Keresiouan } & \text { N.AMERICA } & \text { Miller (1965) } \\ \text { Ainu } & \text { Korean-Japanese } & \text { EURASIA } & \text { Shibatani (1990) } \\ \text { Akan } & \text { Kwa } & \text { AFRICA } & \text { Campbell (1991) } \\ \text { Albanian } & \text { Indoeuropean } & \text { EURASIA } & \text { Buchholz and Fiedler (1987) } \\ \text { Aleut } & \text { Eskimo-Aleut } & \text { EURASIA } & \text { Bergsland (1994) } \\ \text { Amharic } & \text { Semitic } & \text { AFRICA } & \text { Leslau (1995) } \\ \text { Anywa } & \text { Nilotic } & \text { AFRICA } & \text { Reh }(1993)\end{array}$




\begin{tabular}{|c|c|c|c|}
\hline Apalai & Carib & S.AMERICA & Koehn and Koehn (1986) \\
\hline Arabic & Semitic & AFRICA & Ouhalla (1991) \\
\hline Axininca & Equatorial & S.AMERICA & Payne (1981) \\
\hline Jaqaru & Aymaran & S.AMERICA & Hardman (2000) \\
\hline Azerbajianian & S.Turkic & EURASIA & Schönig (1998) \\
\hline Basque & Isolate & EURASIA & Arregi (1999) \\
\hline Beja & Cushitic & AFRICA & Hudson (1976) \\
\hline Berber & Berber & AFRICA & Noyer (1992) \\
\hline Brahui & NW.Dravidian & EURASIA & Elfenbein (1998) \\
\hline Breton & Celtic & EURASIA & Press (1986) \\
\hline Cayuvava & Equatorial & S.AMERICA & Key (1967) \\
\hline Chamorro & W.M.-Polynes. & SE.ASIA/OC. & Chung (1982) \\
\hline Chinook & Penutian & N.AMERICA & Andersen (1977) \\
\hline Choktaw & Penutian & N.AMERICA & Broadwell (2000) \\
\hline Chukchi & Ch.-Kamchatkan & EURASIA & Krause (1976) \\
\hline Chuvash & Bolgar & EURASIA & Johanson and Csató (1998) \\
\hline Didinga & Saharan & AFRICA & Bryan and Tucker (1966) \\
\hline Dumi & Tibetic & SE.ASIA/OC. & van Driem (1993) \\
\hline Dyola & NW.Atlantic & AFRICA & Givón (1975) \\
\hline Elamite & Elamo-Dravidian & EURASIA & Reiner (1969) \\
\hline Evenki & Tungus & EURASIA & Nedyalkov (1994) \\
\hline Fula & W.Atlantic & AFRICA & Arnott (1970) \\
\hline Fur & Fur & AFRICA & Jakobi (1972) \\
\hline Gahuku & Indo-Pacific & AUSTR./NG. & Foley (1986) \\
\hline Georgian & S.Caucasian & EURASIA & Aronson (1982) \\
\hline German & Germanic & EURASIA & \\
\hline Hixkaryana & Carib & S.AMERICA & Derbyshire (1979) \\
\hline Huave & Penutian & N.AMERICA & Stairs and Hollenbach (1969) \\
\hline Inuktitut & Eskimo & EURASIA & Mallon (1991) \\
\hline Jacaltec & Otomanguean & N.AMERICA & Day (1973) \\
\hline Juang & Austroasiatic & SE.ASIA/OC. & Mahapatra (1976) \\
\hline Jyarong & Tibetic & SE.ASIA/OC. & DeLancey (1985) \\
\hline Kalasala & Nuristani & EURASIA & Degener (1998) \\
\hline Kalmyk & Mongolian & EURASIA & Campbell (1991) \\
\hline Kanuri & Saharan & AFRICA & Cyffer (1992) \\
\hline Ket & Isolate & EURASIA & Noyer (1992) \\
\hline Khanty & Ugric & EURASIA & Abondolo (1998) \\
\hline Kilivila & CE.M.-Polynes. & SE.ASIA/OC. & Senft (1986) \\
\hline
\end{tabular}




\begin{tabular}{|c|c|c|c|}
\hline Kiwai & Trans-Fly & AUSTR./NG. & Wurm (1975) \\
\hline Kobon & Trans-NewGuinea & AUSTR./NG. & Davies (1989) \\
\hline Lenakel & CE.M-Polynes. & SE.ASIA/OC. & Tryon (1973) \\
\hline Lithuanian & Balto-Slavic & EURASIA & Eckert et al. (1994) \\
\hline Macushi & Carib & S.AMERICA & Abbott (1991) \\
\hline Mansi & Ugric & EURASIA & Keresztes (1998) \\
\hline Mapudungun & Andean & SE.ASIA/OC. & Grimes (1985) \\
\hline Marathi & Indic & EURASIA & Pandharipande (1997) \\
\hline Maricopa & Hokan & N.AMERICA & Gordon (1986) \\
\hline Maung & Yiwaidjan & AUSTR./NG. & Donohue (1998) \\
\hline Mekeo & Mek & AUSTR./NG. & Jones (1998) \\
\hline Menomini & Algonquian & N.AMERICA & Bloomfield (1962) \\
\hline Mohawk & Keresiouan & N.AMERICA & Bonvillain (1973) \\
\hline Muna & W.M.-Polynes. & SE.ASIA/OC. & van den Berg (1989) \\
\hline Nahuatl & Uto-Aztecan & NAMERICA & Andrews (1975) \\
\hline Nandi & Nilotic & AFRICA & Creider and Creider (1989) \\
\hline Nenets & Samoyed & EURASIA & Salminen (1998) \\
\hline Nimboran & Nimboran & AUSTR./NG. & Inkelas (1993) \\
\hline Nocte & Tibetic & SE.ASIA/OC. & Gupta (1971) \\
\hline Nungali & Djamindjungan & AUSTRIA & Hoddinott and Kofod (1976) \\
\hline Nunggubuyu & Australian & AUSTR./NG. & Heath (1984) \\
\hline Nyangumarda & Pama-Nyungan & AUSTR./NG. & Hoard and O'Grady (1976) \\
\hline Piro & Equatorial & S.AMERICA & Matteson (1965) \\
\hline Portuguese & Italic & EURASIA & Iliescu and Mourin (1991) \\
\hline Quechua & Quechuan & S.AMERICA & Lakämper and Wunderlich (1998) \\
\hline Quileute & Chimakuan & N.AMERICA & Andrade (1922) \\
\hline Saamic & Finnic & EURASIA & Sammallahti (1998) \\
\hline Sanskrit & Indic & EURASIA & Bucknell (1994) \\
\hline Seri & Hokan & N.AMERICA & Marlett (1990) \\
\hline Shinasha & Omotic & AFRICA & Rottland (1990) \\
\hline Somali & Cushitic & AFRICA & El-Solami-Mewis (1987) \\
\hline Sora & Austroasiatic & EURASIA & Baker (1985) \\
\hline Straits & Salish & N.AMERICA & Jelinek and Demers (1994) \\
\hline Swahili & Bantu & AFRICA & Vitale $(1981)$ \\
\hline Tama & Nilotic & AFRICA & Bryan and Tucker (1966) \\
\hline Tamil & S.Dravidian & EURASIA & Annamalai and Steever (1998) \\
\hline Teda & Saharan & AFRICA & Bryan and Tucker (1966) \\
\hline Timucua & Paezan & S.AMERICA & Granberry (1993) \\
\hline
\end{tabular}




$\begin{array}{llll}\text { S.Tiwa } & \text { Tanoan } & \text { N.AMERICA } & \text { Rosen }(1990) \\ \text { Turkana } & \text { Nilotic } & \text { SE.ASIA/OC. } & \text { Dimmendaal (1983) } \\ \text { Tzotzil } & \text { Penutian } & \text { N.AMERICA } & \text { Aissen (1987) } \\ \text { Ubykh } & \text { N.Caucasian } & \text { EURASIA } & \text { Campbell (1991) } \\ \text { Udmurt } & \text { Finnic } & \text { EURASIA } & \text { Salminen (1998) } \\ \text { Urubu-Kaapor } & \text { Tupi-Guarani } & \text { S.AMERICA } & \text { Kakumasu (1991) } \\ \text { Walapai } & \text { Hokan } & \text { N.AMERICA } & \text { Redden (1966) } \\ \text { Wardaman } & \text { Gunwinyguan } & \text { AUSTR./NG. } & \text { Merlan (1994) } \\ \text { Warlpiri } & \text { Pama-Nyungan } & \text { AUSTR./NG. } & \text { Hale (1973) } \\ \text { WesternDesert } & \text { Pama-Nyungan } & \text { AUSTR./NG. } & \text { Noyer }(1992) \\ \text { Winnebago } & \text { Keresiouan } & \text { N.AMERICA } & \text { Greenberg (1988) } \\ \text { Yakut } & \text { N.Turkic } & \text { EURASIA } & \text { Stachowski and Menz (1998) } \\ \text { Yimas } & \text { Nor-Pondo } & \text { AUSTR./NG. } & \text { Foley (1991) } \\ \text { Yukaghir } & \text { Uralic-Yukaghir } & \text { EURASIA } & \text { Campbell (1991) } \\ \text { Yurok } & \text { Ritwan } & \text { N.AMERICA } & \text { Robins (1958) } \\ \text { Zapotec } & \text { Otomanguean } & \text { N.AMERICA } & \text { Pickett (1955) }\end{array}$

\section{Notes}

1 All Georgian data are from Carmack (1997: 315,321). Abbreviations used in the glosses and the text: Aff = affix, $\mathrm{A}(\mathrm{gr})=$ agreement, Asp = Aspect, $\mathrm{D}=$ determiner, $\mathrm{du}$ $=$ dual, exc. $=$ exclusive (plural), fem, $=$ feminine gender, Fut $=$ future tense, GEND $=$ gender, Habit $=$ habitual aspect, IP $=$ Inflectional Phrase, mas = masculine gender, Nom $=$ nominative, $\mathrm{N}(\mathrm{UM})=$ number agreement, NPast $=$ non-past tense, $\mathrm{P}(\mathrm{ER})=$ person agreement, $\mathrm{pl}=$ plural, $\mathrm{PN}=$ person-number agreement, $\mathrm{S}=$ Subject, $\mathrm{S} 1 \mathrm{~s}=$ Subject first person singular, $\mathrm{S} 1 \mathrm{p}=$ Subject first person plural, SAgr $=$ subject agreement, $\mathrm{T}(\mathrm{ns})=$ Tense, $\mathrm{TP}=$ Tense phrase, $\mathrm{VP}=$ verbal phrase

${ }^{2}$ See section 2.2 for more discussion of alignment constraints.

3 Wurm gives only schematic paradigms and does not discuss the meanings and uses of the various tenses. Therefore, I do not attempt to gloss his data.

4 Note that this is not agreement but just the representation of a chain according to the copy theory of movement (Chomsky 1995).

${ }^{5}$ Split agreement corresponds closely to the notion of discontinuous bleeding from Noyer (1992).

${ }^{6}$ The alignment constraints that I use here are formally much simpler than "Generalized Alignment" (GA) as proposed by McCarthy and Prince (1993). This is partly due to expository convenience, and partly to the assumption that affix order constraints require only a small subset of the formal power embodied by GA. All of the following analyses 
can be straightforwardly translated into the richer GA format.

${ }^{7}$ Even in languages where NPs are arguably not arguments this does not mean that the agreement affixes are pronouns. Thus Baker (1996) argues convincingly for Mohawk that in such a case the agreement markers identify empty pronominals and are not themselves incorporated pronouns.

${ }^{8}$ But see the discussion of the Amharic perfect paradigm in section 6 .

${ }^{9} \mathrm{I}$ also checked whether areal factors influence the results. To this aim, I checked the different ordering distribution in the six large geographical areas of the world according to Dryer (1992). According to my data, the preference for the order $\mathrm{P}>\mathrm{N}$ holds in all of these areas. See Trommer (2002a) for the detailed results.

${ }^{10}$ I considered only the cases where SAgr is an affix bound to the verb while Julien also considers other realizations of SAgr. Taking the full range of data into consideration does not change the results. See footnote 21 for a possible explanation for the slight preference of suffixal SAgr.

${ }^{11}$ See section 9 for discussion of functional and historical approaches to affix order.

${ }^{12}$ E.g. causative affixes.

${ }^{13}$ With the difference that a context restriction under their premises does not imply adjacency.

14 Julien's claim seems to concern only syntactic heads, hence inflectional Aspect and Tense and not cases where Aspect is - even though productively - derivational, such as Slavic aspectual prefixes (Spencer 1991: 195, Filip 2002).

${ }^{15}$ An anonymous reviewer claims that all person/number markers are portmanteau affixes expressing agreement and aspect. While this might be an inevitable analysis in a lexicalist theory, it is not in Distributed Morphology, where vocabulary items are underspecified for the syntactic features they realize. I also assume that the different stem shapes are due to morphophonological rules, which is supported by the fact that they are largely governed by lexical classes.

${ }^{16}$ See footnote 3 on the presentation of the Kiwai data.

${ }^{17}$ The first assumption reduces to the claim that finite sentences obligatorily contain Tense (Chomsky 1995: ch.4). While the semantics of the future forms is not clear from Wurm's description, we would expect that they differ on the value of a morphosyntactic feature $F$, which is represented as the head $d u$ - in the indefinite future. That the corresponding value for the immediate future is also projected in the same syntactic position is natural in a model where the semantic content and scope of syntactic heads are reflected in universally fixed base configurations (see section 5).

${ }^{18}$ That Agreement adjoins to Tense is not an idiosyncratic assumption about Kiwai, but is also reflected in the crosslinguistic positioning of Tense and Agreement. See section 7 for discussion.

${ }^{19}$ The structural proximity of Tense and subject agreement is also reflected by the fact that these categories often fuse into portmanteau markers, as discussed for Georgian and Amharic in section 6 . 
${ }^{20}$ This conclusion is drawn for independent reasons in Julien (2000: 214).

21 The preference for suffixal Tense seems to be due to the fact that languages with basic SOV order have a preference for suffixal Tense while SVO and verb-initial languages have no clear preference with regard to afixal status. See section 8 for further discussion of this topic. The preference for suffixal Tense is also a possible explanation for the slight preference for suffixal SAgr in the data of Julien (cf. section 4), since REFLECT favors SAgr and Tense on the same side of the verb.

${ }^{22} \mathrm{~A}$ further extensive study on the position of agreement affixes is Bybee et al. (1990). Bybee et al. (1990) investigate subject and object agreement as a whole without giving different figures for both types of agreement. Since my study is restricted to subject agreement, and Siewierska and Bakker (1996) find significant differences between their ordering properties this study is not taken into account here.

${ }^{23}$ This is roughly in line with the Head Ordering Principle (HOP) proposed by Cutler et al. (1985) and Hawkins and Gilligan (1988). However the HOP is problematic for other types of affixes. See Siewierska and Bakker (1996) for critical discussion.

${ }^{24}$ No percentages are provided since Julien neither gives them nor the total number of genera considered for each word order type, which would allow to compute them.

${ }^{25}$ Note that the occurence of both, preposed and postposed markers in a single language (genus), are possible. Therefore the rows add to more than $100 \%$.

${ }^{26}$ Bybee et al. (1990: 3) call the same assumption "fossilized syntax hypothesis".

${ }^{27}$ See Corbett (2000: 266-68) for an overview.

${ }^{28}$ For example, he finds that "if number is not available for all persons, then it will be found first of all in the first person, then in the second, and in the third only if in both first and second also" (Corbett 2000: 277).

${ }^{29}$ Languages with person and number agreement fall under both categories.

${ }^{30}$ In contrast to my approach, Hyman formulates morphological constraints by means of a (violable) template.

${ }^{31}$ CE. $=$ Central-East, N. = North, NW. = North-West, S. = South , SE. = South-East, $\mathrm{W} .=$ West, OC. $=$ OCEANIA, AUSTR./NG. = Australia/New Guinea, M.-Polynes. = Malayo-Polynesian, Ch.-Kamchatkan $=$ Chukotko-Kamchatkan

\section{References}

Abbott, M. 1991. "Macushi". In D. C. Derbyshire and G. K. Pullum (eds.), Handbook of Amazonian Languages, volume 2. Berlin: Mouton de Gruyter, 23-160.

Abondolo, D. 1998. "Khanty". In D. Abondolo (ed.), The Uralic Languages. London: Routledge, 358-386.

Aissen, J. L. 1987. Tzotzil Clause Structure. Dordrecht: Reidel.

Andersen, S. R. 1977. "On Mechanisms by which Languages Become Ergative". In C. Li (ed.), Mechanisms of Syntactic Change, volume 2. Austin: University of Texas Press, $317-364$. 
Andrade, M. J. 1922. "Quileute". In F. Boas (ed.), Handbook of American Indian Languages, volume 2. Smithsonian Institution, Bureau of American Ethnology, Bulletin 40. Washington: Government Printing Office, 149-292.

Andrews, J. R. 1975. Introduction to Classical Nahuatl. Austin: University of Texas Press. Annamalai, E. and S. B. Steever. 1998. "Modern Tamil". In S. B. Steever (ed.), The Dravidian Languages. London: Routledge, 100-128.

Arnott, D. W. 1970. The Nominal and Verbal Systems of Fula. Oxford: Clarendon Press. Aronson, H. I. 1982. Georgian: A Reading Grammar. Bloomington: Slavica.

Arregi, K. 1999. "Person and Number Inflection in Basque". In V. Lin, C. Krause, B. Bruening and K. Arregi (eds.), Papers on Morphology and Syntax: Cycle Two, volume 34 of MIT Working Papers in Linguistics. Cambridge Mass: MITWPL, 229264.

Baker, M. C. 1985. "The Mirror Principle and Morphosyntactic Explanation". Linguistic Inquiry 16, 537-576.

Baker, M. C. 1996. The Polysynthesis Parameter. Oxford: Oxford University Press.

Bergsland, K. 1994. "Aleut Tenses and Aspects". In C. Bache (ed.), Tense, Aspect and Action: Empirical and Theoretical Contributions to Language Typology. Berlin: Mouton de Gruyter, 323-369.

Bloomfield, L. 1962. The Menomini Language. New Haven: Yale University Press.

Bobaljik, J. D. 2001. "Realizing Germanic Inflection: Why Morphology does not Drive Syntax". Ms., McGill University.

Bonvillain, N. 1973. A Grammar of Akwesasne Mohawk. Ottawa: National Museum of Man.

Broadwell, G. A. 2000. "Choktaw". Ms., University at Albany, State University of New York.

Bryan, M. A. and A. Tucker. 1966. Linguistic Analyses: The Non-Bantu Languages of North-Eastern Africa. Oxford: Oxford University Press.

Buchholz, O. and W. Fiedler. 1987. Albanische Grammatik. Leipzig: VEB Verlag Enzyklopädie.

Bucknell, R. S. 1994. Sanskrit Manual. Delhi: Motilal Banarsidass.

Bybee, J. L. 1985. Morphology. Amsterdam: John Benjamins.

Bybee, J. L., W. Pagliuca and R. D. Perkins. 1990. "On the Asymmetries in the Affixation of Grammatical Material". In W. Croft, K. Denning and S. Kemmer (eds.), Studies in Typology and Diachrony. Amsterdam: John Benjamins, 1-42.

Campbell, G. L. 1991. Compendium of the World's Languages, volume 1. London: Routledge.

Carmack, S. 1997. "Blocking in Georgian Verb Morphology". Language 73, 314-338.

Chomsky, N. 1995. The Minimalist Program. Cambridge Mass: MIT Press.

Chung, S. 1982. "Unbounded Dependencies in Chamorro Grammar". Linguistic Inquiry $13,39-77$.

Cinque, G. 1999. Adverbs and Functional Heads: A Cross-linguistic Perspective. Oxford: Oxford University Press.

Corbett, G. G. 2000. Number. Cambridge Textbooks in Linguistics. Cambridge: Cambridge University Press. 
Cowley, R., M. L. Bender and C. A. Ferguson. 1976. "The Amharic Language". In M. L. Bender, J. Bowen, R. Cooper and C. A. Ferguson (eds.), Language in Ethiopia. Oxford: Oxford University Press, 63-76.

Creider, C. A. and J. T. Creider. 1989. A Grammar of Nandi. Hamburg: Helmut Buske Verlag.

Cutler, A., J. A. Hawkins and G. Gilligan. 1985. "The Suffixing Preference: A Processing Explanation". Linguistics 23 , 723-758.

Cyffer, N. 1992. We Learn Kanuri. Köln: Rüdiger Köppe Verlag.

Davies, J. 1989. Kobon. London: Routledge.

Day, C. 1973. The Jacaltec Language. Bloomington: Indiana University Publications.

Degener, A. 1998. Die Sprache von Nisheygram im afghanischen Hindukush. Wiesbaden: Harrassowitz Verlag.

DeLancey, S. 1985. "An Interpretation of Split Ergativity and Related Patterns" . Language $51,626-657$.

Derbyshire, D. C. 1979. Hixkaryana. Amsterdam: North Holland Publishing Company.

Dimmendaal, G. J. 1983. The Turkana Language. Dordrecht: Foris.

Donohue, M. 1998. "A Note on Verbal Agreement in Maung". Ms., University of Manchester.

Dryer, M. S. 1989. "Plural Words". Linguistics 27, 865-95.

Dryer, M. S. 1992. "The Greenbergian Word Order Correlations". Language 68, 81-138.

Durie, M. 1986. "The Grammaticization of Number as a Verbal Category". In Proceedings of the 12th Annual Meeting of the Berkeley Linguistics Society, 355-370.

Eckert, R., Bukevičiūtè, E.-J. and F. Hinze. 1994. Die baltischen Sprachen. Leipzig: Langenscheidt Verlag Enzyklopädie.

El-Solami-Mewis, C. 1987. Lehrbuch des Somali. Leipzig: VEB Verlag Enzyklopädie.

Elfenbein, J. 1998. "Brahui". In S. B. Steever (ed.), The Dravidian Languages . London: Routledge, 388-414.

Embick, D. 1998. "Voice Systems and the Syntax/Morphology Interface". In H. Harley (ed.), Papers from the UPenn/MIT Roundtable on Argument Structure and Aspect, volume 34 of MIT Working Papers in Linguistics. Cambridge Mass: MITWPL, 41-72.

Filip, H. 2002. "Prefixes and the Delimitation of Events". Ms., Northwestern University.

Foley, W. A. 1986. The Papuan Languages of New Guinea. Cambridge: Cambridge University Press.

Foley, W. A. 1991. The Yimas Language of New Guinea. Stanford: Stanford University Press.

Frajzyngier, Z. 1997. "Grammaticalization of Number: from Demonstratives to Nominal and Verbal Plural". Journal of Linguistic Typology 1, 193-242.

Givón, T. 1975. "Serial Verbs and Syntactic Change: Niger-Congo". In C. Li (ed.), Word Order and Word Order Change. Austin: University of Texas Press, 47-112.

Gordon, L. 1986. Maricopa Morphology and Syntax. Berkeley: University of California Press.

Granberry, J. 1993. A Grammar and Dictionary of the Timucua Language. Tuscaloosa: University of Alabama Press. 
Greenberg, J. H. 1988. "The First Person Inclusive Dual as an Ambiguous Category". In J. H. Greenberg (ed.), Studies in Language. Amsterdam: John Benjamins, 1-18.

Grimes, J. E. 1985. "Topic Inflection in Mapudungun Verbs". IJAL 51, 141-163.

Grimshaw, J. 2000. "Optimal Clitic Positions and the Lexicon in Romance Clitic Systems". In G. Legendre, J. Grimshaw and S. Vikner (eds.), OT Syntax. Cambridge Mass: MIT Press, 205-240.

Gupta, D. 1971. An Introduction to the Nocte Language. Shillong: North-East Frontier Agency.

Hale, K. 1973. "Person Marking in Walbiri". In S. Anderson and P. Kiparsky (eds.), A Festschrift for Morris Halle. New York: Holt, Rinehart and Winston, 308-344.

Halle, M. and A. Marantz. 1993. "Distributed Morphology and the Pieces of Inflection". In K. Hale and S. J. Keyser (eds.), The View from Building 20. Cambridge Mass: MIT Press, 111-176.

Hardman, M. J. 1966. Jaqaru: Outline of Phonological and Morphological Structure. The Hague: Mouton.

Hardman, M. J. 2000. Jaqaru. München: Lincom Europa.

Hawkins, J. and G. Gilligans. 1988. "Left-Right Asymmetries in Morphological Universals". In J. Hawkins and H. Holmback (eds.), Papers in Universal Grammar. Lingua (special issue), 221-244.

Hawkins, J. A. and G. Gilligan. 1988. "Prefixing and Suffixing Universals in Relation to Basic Word Order". Lingua 74, 219-259.

Heath, J. 1984. Functional Grammar of Nunggubuyu. Canberra: Australian Institute of Aboriginal Studies.

Hoard, J. E. and G. N. O'Grady. 1976. "Nyangumarda Phonology: A Preliminary Report". In R. M. Dixon (ed.), Grammatical Categories in Australian Languages. Canberra: Australian Institute of Aboriginal Studies, 51-77.

Hoddinott, W. G. and F. M. Kofod. 1976. "Djamidjungan". In R. M. Dixon (ed.), Grammatical Categories in Australian Languages. Canberra: Humanities Press, 397401.

Hudson, R. A. 1976. "Beja". In M. L. Bender (ed.), The Non-Semitic Languages of Ethiopia, number 5 in Occasional Papers Series. East Lansing: African Studies Center, Michigan State University, 97-132.

Hyman, L. M. 2001. "Templatic and/or Compositional Morphology: Suffix Ordering in Bantu". Paper presented at the Bay Area Typology Workshop, March 17, 2001.

Iliescu, M. and L. Mourin. 1991. Typologie de la Morphologie Verbale Romance. Innsbruck: Verlag des Instituts für Sprachwissenschaft der Universität Innsbruck.

Inkelas, S. 1993. "Nimboran Position Class Morphology". Natural Language and Linguistic Theory 11, 559-624.

Jakobi, A. 1972. A Fur Grammar. The Hague: Mouton.

Jelinek, E. and R. A. Demers. 1994. "Predicates and Pronominal Arguments in Straits Salish". Language 16, 697-735.

Johanson, L. and E. A. Csató. 1998. "Chuvash". In S. B. Steever (ed.), The Turkic Languages . London: Routledge, 434-452. 
Jones, A. 1998. Towards a Lexicogrammar of Mekeo. Canberra: Australian National University Research School of Pacific and Asian Studies.

Julien, M. 2000. Syntactic Heads and Word-Formation: A Study of Verbal Inflection. PhD thesis, University of Troms $\varnothing$.

Kakumasu, J. 1991. "Urubu-Kaapor". In D. C. Derbyshire and G. K. Pullum (eds.), Handbook of Amazonian Languages, volume 1. Berlin: Mouton de Gruyter, 326-406.

Kayne, R. S. 1994. The Antisymmetry of Syntax. Cambridge Mass: MIT Press.

Keresztes, L. 1998. "Mansi". In D. Abondolo (ed.), The Uralic Languages. London: Routledge, 387-427.

Key, H. H. 1967. Morphology of Cayuvava. The Hague: Mouton.

Koehn, E. and S. Koehn. 1986. "Apalai". In D. C. Derbyshire and G. K. Pullum (eds.), Handbook of Amazonian Languages, volume 1. Berlin: Mouton de Gruyter, 33-127.

Krause, S. R. 1976. Topics in Chukchee Phonology and Morphology. PhD thesis, University of Illinois at Urbana-Champaign.

Lakämper, R. and D. Wunderlich. 1998. "Person Marking in Quechua - a Constraint-based Minimalist Analysis". Lingua 105, 113-148.

Lehmann, C. 1995. Thoughts on Grammaticalization, volume 1 of Lincom Studies in Theoretical Linguistics. München: Lincom Europa.

Leslau, W. 1995. Reference Grammar of Amharic. Wiesbaden: Harrassowitz Verlag.

Mahapatra, B. P. 1976. "Comparative Notes on Juang and Kharia Finite Verbs". In P. N. Jenner, L. C. Thompson and S. Starosta (eds.), Austroasiatic Studies, volume 2. Honolulu: University Press of Hawaii, 801-814.

Mallon, M. 1991. Introductory Inuktitut: Reference Grammar. Montreal: Arctic College McGill University Inuktitut Text Project.

Marlett, S. A. 1990. "Person and Number Inflection in Seri". IJAL 56, 503-541.

Matteson, E. 1965. The Piro (Arawakan) Language. Berkeley: University of California Press.

McCarthy, J. and A. Prince. 1993. "Generalized Alignment". In G. Booij and J. van Marle (eds.), Yearbook of Morphology 1993. Dordrecht: Kluwer, 79-153.

McCarthy, J. and A. Prince. 1994. "The Emergence of the Unmarked: Optimality in Prosodic Morphology". In Proceedings of the North East Linguistic Society 24, 333379.

Merlan, F. C. 1994. A Grammar of Wardaman. Berlin: Mouton de Gruyter.

Miller, W. R. 1965. Acoma Grammar and Texts. Berkeley: University of California Press.

Mithun, M. 1991. "The Development of Bound Pronominal Paradigms". In W. P. Lehmann and H.-J. J. Hewitt (eds.), Language Typology 1988: Typological Models in Reconstruction, volume 81 of Current Issues in Linguistic Theory. Amsterdam: John Benjamins, $85-104$.

Nedyalkov, I. 1994. "Evenki". In P. Kahrel and R. van den Berg (eds.), Typological Studies in Negation. Amsterdam: John Benjamins, 1-34.

Noyer, R. R. 1992. Features, Positions and Affixes in Autonomous Morphological Structure. PhD thesis, MIT.

Ouhalla, J. 1991. Functional Categories and Parametric Variation. London: Routledge.

Pandharipande, R. V. 1997. Marathi. London: Routledge. 
Parker, G. 1976. Gramaticá Quechua: Ancash-Huailas. Lima: Ministerio de Educación, Instituto de Estudios Peruanos.

Payne, D. L. 1981. The Phonology and Morphology of Axininca Campa. Dallas: The Summer Institute of Linguistics and the University of Texas at Arlington.

Pickett, V. 1955. "Isthmus Zapotec Verb Analysis II". IJAL 21, 217-232.

Press, I. 1986. A Grammar of Modern Breton. Berlin: Mouton de Gruyter.

Prince, A. and P. Smolensky. 1993. Optimality Theory: Constraint Interaction in Generative Grammar. Technical Reports of the Rutgers University Center of Cognitive Science. RUCCS TR-2.

Redden, J. E. 1966. "Walapai II: Morphology". IJAL 32, 141-163.

Reh, M. 1993. Anywa Language. Köln: Rüdiger Köppe Verlag.

Reiner, E. 1969. "The Elamite Language". In B. Spuler (ed.), Altkleinasiatische Sprachen, Handbuch der Orientalistik. Leiden: E. J. Brill, 54-116.

Robins, R. H. 1958. The Yurok Language. Berkeley: University of California Press.

Rosen, C. 1990. "Rethinking Southern Tiwa: The Geometry of a Triple-Agreement language". Language 66, 669-709.

Rottland, F. 1990. "A Sketch of Shinasha Morphology". In R. J. Hayward (ed.), Omotic Language Studies . London: School of Oriental and African Studies, University of London, 185-209.

Ruhlen, M. 1987. A Guide to the World's Languages: Classification, volume 1. Stanford University Press.

Salminen, T. 1998. "Nenets". In D. Abondolo (ed.), The Uralic Languages. London: Routledge, 516-547.

Samek-Lodovici, V. and A. Prince. 1999. Optima. Technical Reports of the Rutgers University Center of Cognitive Science. RUCCS TR-57.

Sammallahti, P. 1998. "Saamic". In D. Abondolo (ed.), The Uralic Languages. London: Routledge, 387-427.

Schönig, C. 1998. "Azerbaijanian”. In S. B. Steever (ed.), The Turkic Languages . London: Routledge, 248-260.

Selkirk, E. 1995. "The Prosodic Structure of Function Words". In Papers in Optimality Theory, volume 18 of University of Massachusetts Occasional Papers. Amherst: University of Massachusetts, 439-469.

Senft, G. 1986. Kilivila: The Language of the Trobriand Islanders. Berlin: Mouton de Gruyter.

Shibatani, M. 1990. The Languages of Japan. Cambridge: Cambridge University Press.

Siewierska, A. 1993. "The Relationship between Affix and Main Clause Constituent Order". In C. Wilder and D. Cavar (eds.), Word Order Variation, Verb Movement and Economy Principles. Frankfurt a. M.: Johann Wolfgang Goethe Universität, 63-75.

Siewierska, A. and D. Bakker. 1996. "The Distribution of Subject and Object Agreement and Word Order Type". Studies in Language 20, 115-161.

Spencer, A. 1991. Morphological Theory. Oxford: Blackwell.

Stachowski, M. and A. Menz. 1998. "Yakut". In S. B. Steever (ed.), The Turkic Languages. London: Routledge, 417-433.

Stairs, E. F. and B. E. Hollenbach. 1969. "Huave Verb Morphology". IJAL , 38-53. 
Trommer, J. 2002a. Distributed Optimality. PhD thesis, University of Potsdam.

Trommer, J. 2002b. "Modularity in OT-Morphosyntax". In G. Fanselow and C. Féry (eds.), Resolving Conflicts in Grammar: Optimality Theory in Syntax, Morphology and Phonology. Special Issue 11 of Linguistische Berichte.

Tryon, D. T. 1973. "Linguistic Subgrouping in the New Hebridies: A Preliminary Approach". Oceanic Linguistics 12, 303-351.

van den Berg, R. 1989. A Grammar of the Muna Language. Dordrecht: Foris.

van Driem, G. 1993. A Grammar of Dumi. Berlin: Mouton de Gruyter.

Vitale, A. J. 1981. Swahili Syntax. Dordrecht: Foris.

Wunderlich, D. 1996. "Minimalist Morphology: The Role of Paradigms". In G. Booij and J. van Marle (eds.), Yearbook of Morphology 1995. Dordrecht: Kluwer, 93-114.

Wurm, S. A. 1975. "The Trans-Fly Stock". In S. A. Wurm (ed.), New Guinea Area Languages and Language Study: Papua Languages and the New Guinea Linguistic Scene, volume 1 of Pacific Linguistics, Series C, 38. Canberra: Australian National University, $323-344$

Young, R. W. and W. Morgan. 1998. The Navajo Language: A Grammar and Colloquial Dictionary. Albuquerque: University of New Mexico Press.

University of Osnabrück

Institute of Cognitive Science

Katharinenstrasse 24

49078 Osnabrück, Germany

e-mail: jtrommer@uos.de 